\title{
ELECTRIFYING THE MARKET: HOW TRADITIONAL AUTOMAKERS ARE CULTIVATING ELECTRIC BRAND IDENTITIES
}

\author{
by \\ Caelan Warnock \\ Bachelor of Fine Art, 2013, Emily Carr University of Art \& Design
}

\author{
An MRP \\ presented to Ryerson University \\ in partial fulfillment of the \\ requirements for the degree of \\ Master of Professional Communication \\ in the program of \\ Professional Communication
}

Toronto, Ontario, Canada, 2021

(C) Caelan Warnock, 2021 


\section{Author's Declaration}

I HEREBY DECLARE THAT I AM THE SOLE AUTHOR OF THIS MRP. THIS IS A TRUE COPY OF THE MRP, INCLUDING ANY REQUIRED FINAL REVISIONS. I AUTHORIZED RYERSON UNIVERSITY TO LEND THIS MRP TO OTHER INSTITUTIONS OR INDIVIDUALS FOR THE PURPOSE OF SCOLARLY RESEARCH. I FURTHER AUTHORIZE RYERSON UNIVERSITY TO REPRODUCE THS MRP BY PHOTOCOPYING OR BY OTHER MEANS, IN TOTAL OR IN PART, AT THE REQUEST OF OTHER INSTITUTIONS OR INDIVIDUALS FOR THE PURPOSE OF SCOLARALY RESEARCH. THE PUBLIC. 


\begin{abstract}
This research project looks at the marketing language and brand integration strategies used with electric vehicles (EVs) by traditionally internal combustion-based (ICE) automobile manufacturers. A comprehensive keyword and thematic analysis of manufacturer webpages was conducted to understand the current market positioning of EVs compared with their ICE counterparts. Identified keywords and themes were then considered alongside an NLP sentiment analysis and keyword analysis of 60,291 Twitter tweets. Results indicate Twitter users express more polarized viewpoints with regard to EVs than ICEs, and that EV advertising language is less market specific then that of ICEs. In public discourse, functional attributes highlighted by manufacturers feature more prominently than sustainability-focused attributes, such as environmental impact and the use of sustainable materials. It is apparent manufacturers are still struggling to differentiate their EV products and are being used as a marketing tool by manufacturers to conceptually justify personal automobile ownership and promote CSR priorities.
\end{abstract}

Keywords: EV, BEV, electric vehicle, automotive, automotive branding, marketing 


\section{Acknowledgements}

The technical elements in this paper were made possible by open-source Python code and practices made available to the public by Jessica Uwoghiren, Martin Beck, Yalin Yener, JustAnotherArchivist (see Bibliography). 


\section{Dedication}

I dedicate this research paper to my parents. My father Roderick whose infectious love of learning inspired me to pursue this, and many other, projects. As well as my mother Susan, whose steadfast determination taught me to always challenge yourself. I also want to thank my partner Elizabeth for her tremendous support throughout this entire year. 


\section{Table of Contents}

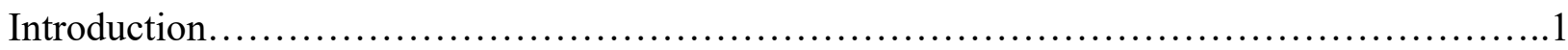

Literature Review

Branding and Integration of Disruptive Technologies.............................

EVs are Radically Different from Traditional Automobiles...........................5

Consumer Expectations and the Importance of Brand Value Alignment................6

Brand Attachment, Experiential Positioning and Harnessing Motorsport................8

Environmental Policy and Government Mandates...............................12

The Challenges of Branding with Corporate Social Responsibility....................15

Research Questions............................................................ 18

Methodology

Defining the Sample Pool....................................................19

Analysis of Manufacturer Language of EV and ICE Products.......................20

Analysis of Public Discourse \& Sentiment using Twitter.........................21

Analysis

Quantitative \& Qualitative Evaluation of Automaker Product Descriptions.............26

Chevrolet..........................................................27

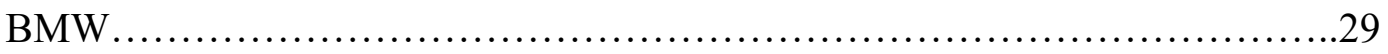

Audi.................................................................. 30

Nissan................................................................ 33

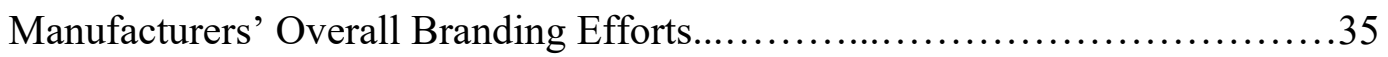

Identify Public Perception using Twitter.......................................... 37 
Sentiment Analysis............................................... 38

Keyword Analysis.................................................... 39

Chevrolet...........................................................41

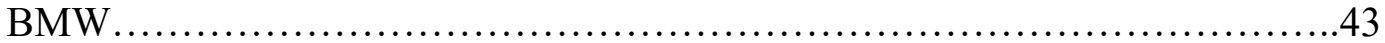

Audi.................................................................. 45

Nissan.................................................................47

Conclusion............................................................... 49

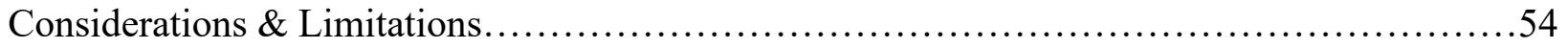

Contributions \& Future Research..........................................................

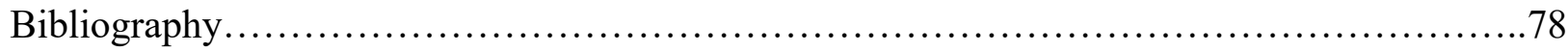

List of Tables........................................................................... vii

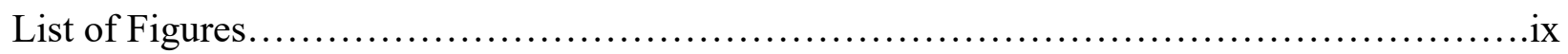

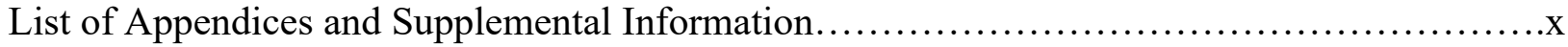




\section{List of Tables}

Table 1. Most popular descriptive adjectives used by manufacturer per model................26

Table 2. Number of Unique Tweets in EV Sample per model..............................37

Table 3. Number of Unique Tweets in ICE Sample per model...............................37

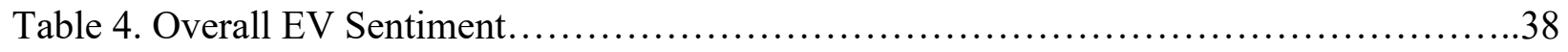

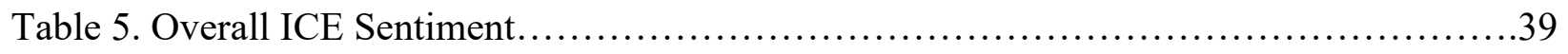

Table 6. Most Popular Descriptive EV Adjectives Tweeted per model.....................40

Table 7. Most Popular Descriptive ICE Adjectives Tweeted per model......................40

Table 8. Most popular EV bigrams from Twitter sample by model.........................57

Table 9. Most popular EV trigrams from Twitter sample by model........................58

Table 10. Most popular ICE bigrams from Twitter sample by model.......................59

Table 11. Most popular ICE trigrams from Twitter sample by model.......................60 


\section{List of Figures}

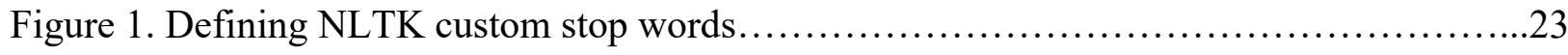

Figure 2. Information extracted from Twitter data......................................24

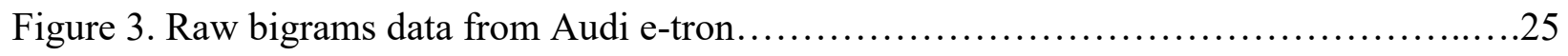

Figure 4. Most Common Keywords: Bolt \& Silverado...............................41

Figure 5. Most Common Keywords: i3 \& X3 ........................................43

Figure 6. Most Common Keywords: e-tron \& Q5 ...................................45

Figure 7. Most Common Keywords: Leaf \& Rogue.....................................47 


\section{List of Appendices and Supplemental Information}

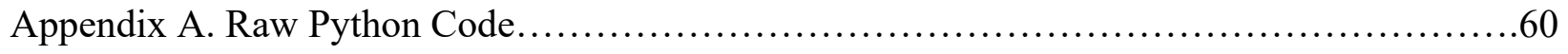

Appendix B. Chevrolet Bolt Manufacturer Analysis \& Adjectives..........................67

Appendix C. BMW i3 Manufacturer Analysis \& Adjectives..............................68

Appendix D. Audi e-tron Manufacturer Analysis \& Adjectives................................69

Appendix E. Nissan Leaf Manufacturer Analysis \& Adjectives...............................70

Appendix F. Chevrolet Silverado Manufacturer Analysis \& Adjectives......................71

Appendix G. BMW X3 Manufacturer Analysis \& Adjectives...............................72

Appendix H. Audi Q5 Manufacturer Analysis \& Adjectives................................73

Appendix I. Nissan Rogue Manufacturer Analysis \& Adjectives...........................74

Appendix J. Most Tweeted Words.............................................. 75

Supplemental Information 1. HMTL data mining results

Supplemental Information 2. Manufacturer Confirmatory Analysis Matrices 


\section{Introduction}

Electric vehicles have grown in popularity over the past decade (Morgan, 2020), fueled in part by aggressive marketing employed by EV-only manufacturers such as Tesla Inc (Hardman, 2015), advancements in battery technology, governmental environmental initiatives (Morgan, 2020), and shifting consumer demand (Dehkordi et al., 2013). Moreover, EVs have drastically different qualities when compared with their internal combustion engine (ICE) counterparts, both in concept and in functionality (Gärling \& Thøgersen, 2001). This frequently results in ineffective marketing and communication strategies and branding (Khraim, 2020), with "quantitative and qualitative research results confirm[ing] that consumers are [often] confused about [an] EVs nature and functional characteristics (Krause et al., 2013; Axsen et al., 2017 as cited by Khraim, 2020, pg. 14).

The marketing and communication strategies adopted by leading ICE automobile manufacturers to integrate these new types of products into their existing brand identities vary from futuristic, electricity-inspired names to entirely new sub-brands. As recently as 2021, General Motors (GM) launched a new branding campaign that featured an updated GM logo to distinguish its battery-operated vehicle (BEV or EV) line-up, "mark[ing] only the fifth time the automaker has updated its corporate look in 113 years and [constituting] the most aggressive change since 1964" (Shultz \& Lutz, 2021, para. 2). The updated look attempts to distance the manufacturer from its American muscle car and pickup truck roots, shifting to a more "approachable tone as it pushes out EVs geared for consumers of all income levels" (Shultz \&

Lutz, 2021, para. 2). BMW has taken a similar approach, focusing heavily in recent years on 
launching its EV sub-brand "BMW i", which it advertises as "visionary electric vehicles and mobility services, inspiring design and a new understanding of premium that is strongly defined by sustainability" (BMW, 2021). Lincoln Motors, another American manufacturer, has also adopted strategic communication efforts to successfully integrate EVs by adopting the Grand Touring moniker, "a phrase made popular by European sports cars from the 1950s" (Martinez et al., 2019, para. 11), in an attempt to redirect consumer "focus [to] the vehicles' performance capabilities and dispel the image of hybrids as weak fuel-sippers" (Martinez et al., 2019, para. 12). All manufacturers are facilitating the evolution of their traditional brand identities in order to cultivate unique, EV-focused identities in a highly competitive and rapidly changing marketplace. By reflecting upon the efforts taken by automakers, it is clear that EV technology represents a major "disruptive force" (Hardman, 2014, pg. 1627) within the auto industry, one that demands decidedly new marketing and communication strategies.

\section{Literature Review}

To understand the challenge EVs pose to automotive manufacturers, we need to understand how consumers view EVs, the changing automotive landscape, and the role of brand identity in the automotive marketplace. Existing research on the topic roughly falls into the thematic categories below, each considered as a basis of knowledge to guide subsequent research. 


\section{Branding and Integration of Disruptive Technologies}

To understand the extent to which EV products affect consumer brand perception following their introduction into traditional automotive portfolios, we must first examine the new challenges presented to automotive manufacturers when marketing this new technology as a whole. Cooper (2000) offers a thorough situational analysis of the challenges faced when introducing "radically new products" that "change the dimensionality of the consumer decision" (Cooper, 2000, pg. 1). Cooper used the American electric vehicle industry as a case study, first by identifying scenarios that affect the dimensionality of the automobile market. The results were integrated with economic data surrounding EVs and then mapped using a Bayesian network, a probabilistic graphical model, "that can be updated as events unfold and used to simulate the impact that changes in assumptions underlying the web have on the prospects for the new product" (Cooper, 2000, pg. 1). This strategy proved useful for identifying areas of interest that automobile manufacturers must consider when introducing radically new EV products.

While Cooper's study identifies several pertinent marketing concerns manufacturers must consider as they enter the EV marketspace, his study has several limitations with regard to our scope of research. Firstly, Cooper's broader approach doesn't specifically evaluate the potential impact of introducing EV products into an existing automobile product portfolio. Additionally, when quantifying "Consumer Demand", the study focuses on three subthemes of "issues pertaining to education and information, [...] value proposition $[\ldots]$, and social acceptance" (Cooper, 2000, pg. 8). This limits our ability to measure effects on brand perception, as it does not specifically consider prior brand positioning as a factor (or as a part of the "value 
proposition") that may affect successful reception. This method of qualitative mapping may be useful if reconfigured to specifically reflect existing marketing efforts.

In a similar study also focusing on disruptive technologies in the automotive industry, Hardman et al. (2015) position Tesla, Inc., as a case study in order to evaluate their successful "high-end encroachment market entry strategy" (Hardman et al., 2015, pg. 1) and its potential to be utilized by fuel cell vehicle (FCV) manufactures. This research is applicable because many of the qualities that apply to introducing FCVs also apply to the introduction of an EV lineup. Like the study conducted by Cooper (2000), EV technology was identified and measured as a "disruptive technology" (Hardman et al., 2015, pg. 3) with unique factors that must be considered when determining initial brand positioning within a traditional automotive product portfolio. One obvious limitation of this study is that Tesla, Inc., has no prior reputation as a manufacturer of ICE automobiles, and "prior to the introduction of the Tesla Roadster there was no market for EV sport cars" (Hardman et al., 2015, pg. 11). This makes it impossible to evaluate changes in perception of brand identity because there was no shift in portfolio offerings. The study does acknowledge the importance of branding in the automotive world, suggesting that Tesla's strong brand image allows them to retain "brand equity due to them being viewed as 'cool'” (Hardman, 2015, pg. 11). This is largely due to many successful aggressive marketing efforts as outlined by Hardman et al. (2015), even if specific features are not well-received. 


\section{EVs are Radically Different from Traditional Automobiles}

Electric vehicles are a markedly different product than traditional ICE automobiles, both in design and capability. A sentiment reinforced by Gärling \& Thøgersen (2001), whose research notes that EVs come with several significant disadvantages when compared with their ICE counterparts, including range, charging times and high initial cost (Gärling \& Thøgersen, 2001). Each of these disadvantages requires a specific communication strategy to mitigate consumer concerns.

Bennett et al. (2016), using qualitative analysis of opinions from a survey of 645 drivers of ICE vehicles, together with communication efforts by auto manufacturers, sought to identify specific combinations of characteristics of EVs that motorists would regard as important when buying an electric car. Their research highlights several factors that influence prospective EV consumers compared with ICE consumers; EV driving experience ranked as the most important factor, followed by the need for reassurances about range capability (Bennett et al., 2016).

To understand how these EVs are being marketed to consumers, Bennett et al. (2016) conducted a semantic network analysis of manufacturer promotional materials focusing on "word frequency, word co-occurrence and word proximity" (Bennett et al., 2016, pg. 66). They sought to identify key semantic concepts, which were then compared against a categorical content analysis of manufacturer's marketing material, to identify key themes. Of all the factors identified in the survey by consumers as important to their decision to purchase an EV, only driving experience was emphasized in auto manufacturer EV marketing materials (Bennett et al., 2016). While not comprehensive, this study affirms the need to understand how auto 
manufacturers can leverage their existing brand identity in order to minimize these concerns for consumers. While this study identified factors important to new EV consumers, it omitted preexisting EV customers. Now that the EV marketspace has become more established, a larger pool of experienced EV consumers has the potential to offer nuanced insight into the importance of different marketing strategies.

\section{Consumer Expectations and the Importance of Brand Value Alignment}

Due to the unique nature of EVs, Khraim's quantitative study highlights the "potential effect of consumer knowledge of electric vehicles, perceived risk, functional characteristics of EVs, [and] attitude towards EVs [have] on consumer post-purchase dissonance" (Khraim, 2020, pg. 13). Examining survey results from 268 respondents, Khraim identifies several clear areas that potentially influence post-purchase dissonance and illustrates "that functional characteristics, knowledge, and attitude have a statistically significant effect on post-purchase dissonance while concerning the perceived risk of [an] EV [purchase]" (Khraim, 2020, pg. 13). However, the study fails to establish how closely a consumer's existing knowledge of the automotive company's branding influenced their expectations of their EV purchase, nor if that alignment affected their perception of the automotive brand overall.

Automakers must be cognisant of the traditional branding strategies associated with comparable ICE models and consider this when positioning their new EVs. Particularly with EVs, where manufacturer marketing efforts are often focused on more ecologically conscious consumers due to value compatibility (Gärling \& Thøgersen, 2001). Conflicts between 
traditional brand positioning strategies and new ecological benefits have the potential to cause value incompatibility, and thus poor brand alignment (Gärling \& Thøgersen, 2001).

An example that highlights the importance of brand value alignment, specifically in the SUV market, is GM's Hummer brand. The Hummer, or High Mobility Multi-Purpose Wheeled Vehicle ("HUMMVEE"), is a military vehicle that gained consumer popularity during the early 1990s, particularly after news coverage of them in use during the Gulf War (Turnbull, 2014). Originally designed as the US military's replacement for the Jeep (Turnbull, 2014), the Hummer brand, an adapted version for the consumer market, gained recognition with notable endorsements from celebrities (Davis, 2020) during a time of exceptionally low gas prices (US Energy Information Administration, 2004). However, as consumers moved towards more ecologically friendly choices, criticism grew of the Hummer brand because, as noted by Davis (2020), the Hummer brand identity closely aligned itself with its "outlandishly masculine aesthetic" (Davis, 2020, para. 8). After a late-90's cultural shift in North America, particularly after "metrosexuality" (Davis, 2020, para. 9) became a socially accepted lifestyle choice for heterosexual men, the Hummer brand fell out of favor. It became regarded as "uselessly macho" (para. 17) and as a “cartoonish relic of old masculinity that hadn't yet stopped to second-guess itself' (Davis, 2020, para. 17). This cultural shift, along with markedly low gas mileage, poor reliability, an image as an exceptionally un-ecofriendly vehicle (Davis, 2020), and "GM [filing] for bankruptcy in 2009" (para. 19), all led to the Hummer brand being "dismantled the following year" (Davis, 2020, para. 19). 
But recently, GM has announced their intention to capitalize on the Hummer's notoriety as an exceptional polluter by transforming the Hummer brand into a series of all-electric utility vehicles (EUVs) (GM, 2020). HUMMVEEs, along with the Hummer namesake, have become cultural icons in North America, maintaining deep brand penetration among their primary consumers base (Luedicke, 2006). The ironic nature of GM's brand repositioning strategy may prove effective at launching a new all-electric lineup while simultaneously cultivating brand value realignment towards a more ecologically conscientious identity.

\section{Brand Attachment, Experiential Positioning \& Harnessing Motorsport}

As noted by Parment (2015) and reinforced by Bennett et al. (2016), "attachments to brands are consciously and unconsciously established long before a potential buyer considers purchasing a car for the first time" (Parment, 2015, pg. 149). Citing industry examples from Mercedes and Audi, Parment (2020) describes how automotive brands have continuously shifted branding strategies to cope with new markets and the incorporation of new technologies. For example, the launch of the A Class in 1997, the first Mercedes entry into the "small family car" market (Parment, 2015, pg. 85). Focusing on EVs specifically, research suggests there is potential for utilizing a brand's experiential positioning to effectively market to prospective EV consumers using “designed anticipated experiences” (Moons et al., 2014, pg. 226).

To measure how effective cultivated, anticipated experiences could be implemented with EVs, Moons conducted a qualitative exploratory analysis to identify types of anticipated experiences, resulting in three categories: "behavioral, sensory and intellectual" (Moons et al., 
2014, pg. 221). Specifically, the behavioral category speaks to the features which enhance the driver's ability to feel at one with the car. For example, by the driver may change the "behaviour" of the car by changing the mode from sport to comfort. The sensory category encompasses features that emphasize the driver's sensory experience, such as a quiet cabin with a superior quality sound system. The intellectual category refers to more conceptual features that enhance the owner/ driver experience, such as prominent "eco" branding, or blue lighting that visually reflects the vehicle's electric nature. After creating a list of popular EV attributes, the list was then categorized by type of experience. The resulting list was then conjointly analyzed and given a score depending upon the feature's likelihood to promote an exclusive association with any of the three categories of experience (Moons et al., 2014). The study found that while "a behavioural experiential electric car type could not be identified" (pg. 227), intellectual and sensory experiences were apparent, and that automotive "characteristics could thus be used to develop experientially different electric car brand propositions" (Moons et al, 2014, pg. 227).

Experiential consumer positioning, especially utilizing behavioural experiences, has long been an effective tool for automotive marketing and is especially apparent in the marketing efforts of Sport Utility Vehicles (SUVs) (Moons et al., 2014). SUV advertising campaigns often feature the vehicle symbolically dominating nature in "aggressive contexts of strength, speed, agility and power with a variety of wild predators" (Gunster, 2005 as cited by Chen, 2016). This type of experiential positioning allows cars to act "as signifiers of technology that would enable drivers a seamless adaptation to the wild nature by enhancing particular physical attributes such as speed, power, and agility" (Gunster, 2005, Gunster, 2007 as cited by Chen, 2016, pg. 17). This type of advertising has become synonymous with automotive branding and has been leveraged 
successfully by Tesla. By emphasizing the Tesla Roadster's power and speed, Tesla was able to harness the pervasive hyper masculinity of North American car culture to effectively combat the weak public perception of EVs. However, this is a decidedly different approach to many EV manufacturers, who have chosen less traditional branding strategies.

North American car culture (and its embrace of hyper-masculinity) has long been influenced and informed by motorsport, as seen through sporty automotive styling, and its regular appearance in advertisements. With manufacturers desperately trying to enhance the beleaguered public image of EVs, hyper-masculine, speed and power-centric motorsport is an obvious avenue for manufacturers to cultivate new, positive EV brand identities. Motorsport has historically been a way for automakers to use experiential positioning to market their desired brand identity, especially using behavioral (language from commentators, manufacturers) and sensory experiences (audience/spectators). Additionally, it provides an avenue for automakers to align their new products firmly with the mainstream of North American car culture.

Formula 1, for example, is "a high-profile sport, with a [global audience of] 100 million for each race" (Rosenberger \& Donahay, 2008, pg. 2) offering massive branding potential. The annual motorsport competition circuit is, "besides the FIFA World Cup ${ }^{\mathrm{TM}}$ or the Olympic Games, $[\ldots]$ the only event with a comparable global character taking place in 17 countries all over the world" (Woisetschläger, 2007, pg. 616). However, "motor sport has long suffered from negative criticisms because of its unsustainable patterns of consumption contributing to global environmental change" (Robeers, 2019, pg. para.1), both practically and symbolically (Tranter, 2009). This has led to some manufacturers, such as "Volkswagen and subsidiary brands Audi 
and Porsche [to pull] out of major motor sport commitments" (para. 1), such as the "World Endurance Championship series-leading LMP1-class (Le Mans Prototype 1)” (Robeers, 2019, para. 1), instead investing in Formula E sponsorship.

Branding has always been an important component of Formula 1, and by extension Formula E, especially since "motor sport fans, $[. .$.$] can be up to three times more brand loyal than fans of$ other sports, and [...] are also known to switch product loyalties to a sponsor's brand and avoid brands that cease sponsoring their team" (D’Orio 1997, Performance Research 2000, Petrecca 2001, JMU 2005, Phipps 2005a, Thomaselli 2006 as cited by Rosenberger \& Donahay, 2008, pg. 2). Formula $\mathrm{E}$ has created an avenue for automakers to promote their new ecologically focused brand identities, while simultaneously "redirect[ing] operations (and legitimacy) as a function of electric vehicle development" (Robeers, 2019, para. 1). In addition to capitalizing on patterns of potential consumer loyalty while establishing a new electric brand, motorsport provides manufactures a unique opportunity to utilize experiential positioning techniques perfected within Formula 1 to dispel traditional concerns about EVs, such as range, power, sportiness, etc. (Gärling et al., 2001).

Woisetschlager's (2007) research reaffirms participation as a Formula 1 sponsor leads to "statistically significant positive influence on the likelihood [the sponsor] is to be recalled [by the audience]" (Woisetschläger, 2007, pg. 618). This positive effect is influenced by several factors, “event-related involvement [being the] highest, followed by brand equity and product-related involvement" (Woisetschläger, 2007, pg. 618). Based on these findings, it can be assumed that if Formula E can be successfully marketed to, and adopted by, motorsport audiences as an 
equivalent, alternative to Formula 1, then automotive brands can use team sponsorship to effectively integrate electrified vehicles into their brand image.

Similar strategies of brand attribute diversification have been used in the past, notably with automaker Toyota (Woisetschläger, 2007). As noted by Woisetschläger (2007), “Japanese brands

[in Germany] are valued for their functional attributes but are evaluated poorly concerning [their] non-attribute-based image" (Vogel et al. 2006 as cited by Woisetschläger, 2007,pg. 616). Thus, Toyota's main objective through sponsorship of a Formula 1 team is to "improve its nonattribute-based image” (Toyota, 2005 as cited by Woisetschläger, 2007,pg. 616) including "personality and character, attractiveness and likeability" (pg. 616), especially within the European marketspace. When viewed in conjunction with research by Robeers (2019), Formula E team sponsorship offers a potential avenue for early adopters to increase EV brand equity and encourage consumer EV brand association with traditional "motorsport" characteristics such as speed, technological design, handling and "coolness" factor. Chevrolet, and its parent company GM, are the only manufacturer in our sample group that does not currently sponsor a Formula E team.

\section{Environmental Policy and Government Mandates}

A vital component when discussing the introduction of EV technology is the current shift in consumer demand focusing on environmental policy and corporate social responsibility. As noted by the United Nations-led Intergovernmental Panel on Climate Change (IPCC), "to avert catastrophic sea level rise, food shortages, and widespread drought and wildfire, emissions must 
be reduced by 45 percent from 2010 levels, and by 100 percent by 2050” (Bellan, 2018). As seen in a study conducted by the Electrical Power Research Institute (2007) and the Natural Resources Defense Council (of Ireland), it was "concluded that regardless of the electricity supply, [adopting] PHEVs and HEVs would result in a net decrease in GHG emissions of between 28\% and 67\% relative to ICEs" (Brady and O'Mahoney, 2011). Studies such as these demonstrate the potential EVs possess to reduce greenhouse emissions, if paired with proper policy and available, appropriate supporting infrastructure (Brady and O'Mahoney, 2011). At the same time, EVs have been criticized for delaying progressive environmental initiatives by continuing to promote personal vehicle ownership, rather than other more sustainable alternatives such as public transit.

This has led political leaders and lawmakers to push for the rapid adoption of these new technologies. While a formal ICE phase-out date has not been set for the EU, several manufacturers are already anticipating significant changes in the marketplace including "Volvo and Ford [who] have said they will cease selling polluting cars on the Continent from 2030" (Posaner, 2021, para. 14). An online poll commissioned by Belgian campaign group Transport \& Environment (T\&E) conducted by data analytics firm YouGov "surveyed 10,050 people online across 15 of some of Europe's largest cities in eight countries" (Bannon, 2021, para. 1). The study focused on "Belgium, France, Germany, Hungary, Italy, Poland, Spain, and the UK" (para. 1), demonstrating that an EU policy ban on ICE vehicles has strong support with " $63 \%$ of city dwellers support[ing] only emissions-free cars being allowed to be sold after 2030" (Bannon, 2021, para. 1). This sentiment echoes recent independent policy decisions from countries around the world that are attempting to respond to public concern about the growing effects of climate change. In Europe, “Germany's Bundesrat federal council agreed to ban fossil fuel powered 
vehicles by 2030" (para. 7) with the "country is aiming to reduce its CO2 emissions by 95\% by 2050" (Dugdale, 2018, para. 8). This trend is mirrored in France, where Environment Minister Nicolas Hulot "announced plans to ban all petrol and diesel cars by 2040, in addition to phasing out oil and gas production" (para. 12) with the "goal of becoming carbon-neutral by 2050" (Dugdale, 2018, para. 11). Many individual cities have instituted their own ICE regulations, such as Amsterdam, and have pledged ambitious zero-emission goals as soon as 2030 (Boffey, 2019). In the United States, President Joseph Biden committed to "spurring demand by converting the federal government's enormous fleet of vehicles into clean vehicles and supporting electric transit systems and school buses" (Biden, 2021). Governor Gavin Newsom of the US state of California "issued an executive order requiring sales of all new passenger vehicles to be zeroemission by 2035 " and "heavy-duty vehicles shall be 100 percent zero emission by 2045 where feasible, with the mandate going into effect by 2035 for drayage trucks" (State of California, 2021, para. 4). Similar progressive policies can be found around the world (Dugdale, 2018), and as evidenced by policy planning and present political sentiment, the automotive landscape in developed nations will rapidly shift towards an electric future in the coming decades.

In addition to public policy, continued government subsidies for EV purchases (Transport Canada. 2020), investment in infrastructure (Government of Canada, 2021), preferential treatment in city traffic (Government of Ontario, 2013) and various consumer incentives to continue to drive EV market growth. These government subsides also reinforce and encourage the public perception that EVs are the most sustainable transportation option that we must adopt, in turn helping the marketing efforts of sustainability-focused automakers. 


\section{The Challenges of Branding with Corporate Social Responsibility}

As noted by Gärling \& Thøgersen, "besides supportive national policies, skillful marketing is needed to get [EVs] accepted and diffused throughout society" (Gärling \& Thøgersen, 2001, pg. 53). This is increasingly important in a world where, as noted by Chen (2016), growing public environmental concern has ethically called into question our reliance on personal automobiles (Chen, 2016). Automakers have responded by marketing their products using concepts such as “"energy efficiency" and "earth friendly" to continue the promotion of private car ownership" (Chen, 2016, pg. 12).

As discussed, encouraging the public to adopt new and unfamiliar technology can prove extremely difficult (Cooper, 2000). Researchers Ottman, Stafford and Hartman (2010) explore the challenges when branding products as "green product[s]" and "environmental products" (Ottman, Stafford \& Hartman, 2010, pg. 24). Recognizing that "no consumer product has a zero impact on the environment," companies are still able foster a socially responsible brand identity by promoting products that "strive to protect or enhance the natural environment by conserving energy and/or resources and reducing or eliminating use of toxic agents, pollution, and waste" (Ottman, Stafford \& Hartman, 2010, pg. 24). However, these "green" branding efforts only appeal to "the deepest green niche of consumers" (pg. 24) and often "green appeals are not likely to attract mainstream consumers unless they also offer a desirable benefit, such as cost-savings or improved product performance" (Ottman, Stafford \& Hartman, 2010, pg. 24). There are also criticisms of using a "green" agenda to market consumer products, as these "green" efforts only 
provide marginal environmental benefit while significantly guiding the public away from more impactful options, such as public transit development.

This aligns with an analysis conducted by Robeers (2019) of the initial three 2014 ITV Formula E broadcasts, which found that environmental sustainability only featured prominently at the beginning of the series, and throughout the broadcasts "the 'strong ecological message' frame decreases sharply" (Robeers, 2019, para. 15). Robeers attributes this to several factors, noting that while environmental sustainability is mentioned positively throughout the broadcasts by commentators, "the level of detail in terms of context surrounding this suggested importance of [environmental sustainability] is limited" pointing to "a missed opportunity to significantly advance the climate story" (Robeers, 2019, para. 18). In many ways this study reveals the general challenges that come with marketing a product primarily on its ecological benefit; a sustainable product may have a proven collective benefit, but adoption will depend on how it impacts individual lifestyles.

Building from this idea, automakers focusing too heavily on sustainability run the risk of falling victim to Marketing Myopia, a term coined by Theodore Levitt in the 1960 edition of the Harvard Business Review. Levitt (1960) describes a business culture where leaders become so fixated on managing products themselves that they inevitably lose sight of the needs and wants of the consumer (Levitt, 1960). Considering the significant disadvantages that many EVs possess compared with their ICE equivalents (Gärling \& Thøgersen, 2001), it is particularly important for automakers to remain focused on communicating the unique benefits EVs offer and how they can improve the consumer's life. As noted by Ottman, Stafford \& Hartman, "marketers' myopic 
focus on their products' "greenness" over the broader expectations of consumers or other market players (such as regulators or activists)" (Ottman, Stafford \& Hartman, 2010, pg. 24) has led to product failures in the past.

The detriment of marketing myopia can be seen when reflecting upon the General Motors EV-1 and Ford's Think Mobility EV line (Ottman, Stafford \& Hartman, 2010). Developed in response to early "green" policy initiatives in California, these vehicles ultimately failed despite aggressive marketing because "most drivers were not willing to drastically change their driving habits and expectations to accommodate electric cars, and the products ultimately were taken off the market" (Ottman, Stafford \& Hartman, 2010, pg. 25). This is in sharp contrast to the Toyota Prius, a PHEV that won Mototrend's Car of the Year in 2004 (Allison, 2003) despite analysts indicating "that it can take 5 to 20 years for lower gas expenses to offset many hybrid cars' higher prices" (Ottman, Stafford \& Hartman, 2010, pg. 25). The initial popularity of the Prius was driven less by "greenness", but rather by California legislation that allowed a "small number of gas-electric hybrids to use California's carpool lanes with only the driver on board" (O'Dell, 2005, para. 1), "fewer fill-ups" (pg. 26), as well drivers being "granted free parking" (Ottman, Stafford \& Hartman, 2010, pg. 26). Additionally, other non-green benefits made the Prius appealing, including "the dazzling digital dashboard that offers continuous feedback on fuel efficiency" and the (successfully marketed) perception that consumers were "driving the latest technology" (Ottman, Stafford \& Hartman, 2010, pg. 26). The Prius, being a hybrid electric vehicle, also meant consumers didn't have to make any concessions in lifestyle (such as trading accessible gas stations for elusive charging stations) but could still benefit from the car's ““"conspicuous conservation” [that] satisfied many drivers' desires to turn heads and make a 
statement about their social responsibility" (Ottman, Stafford \& Hartman, 2010, pg. 26). The Toyota Prius illustrates that new automotive technology can be readily accepted in the public sphere, if the technology offers a greater individual benefit beyond ecological sustainability.

\section{Research Questions}

There is a lack of research surrounding the impact of electric vehicles have upon the brand identities and marketing strategies of traditional automobile makers, an area that requires further inquiry (Moons et al., 2014). As shown in the above literature review, It is clear that EVs represent a challenging new product for automobile manufacturers, one that requires a decidedly different approach to market effectively. Therefore, it is necessary to understand how automobile manufacturers are marketing EVs given that they represent radically different brand values than their traditional ICE offerings. This study responds to the need to examine EV marketing and attempts to define:

1) How are the most popular ICE automobile manufacturers marketing and advertising their EVs to consumers?

2) How are these EVs perceived by the public, and does public perception align with manufacturer branding/marketing? 


\section{Methodology}

To explore and evaluate the current strategies automotive manufacturers are using to cultivate EV brand identities and market these new products, a brand-level keyword and thematic analysis of language currently employed by industry-leading auto manufacturers was conducted.

\section{Defining the Sample Pool}

To narrow the scope of research, this study focuses on the most popular $2020 \mathrm{EV}$ models by number of total North American sales; the Chevrolet Bolt, the Nissan Leaf, the Audi e-tron, and the BMW i3 (Argon Laboratory, 2020). Collectively, these four models represent the majority of EV vehicles purchased in North America, when excluding Plug-In Hybrid Electric Vehicle (PHEV) and Hybrid options, as well as BEV-only manufacturer Tesla Inc (Argonne National Laboratory, 2020). Additionally, the reputations of these four manufacturers span several diverse market segments (Evanschitzky \& Woisetschlager, 2016) allowing us to gain a broad overview of the effectiveness of EV branding efforts as a whole in the current marketplace. Despite offering the most popular EV in 2020, the Tesla Model 3, EV-only manufacturer Tesla Inc will not be included in the primary dataset. Because the intent of this study is to gain meaningful insight into how traditional ICE automakers have cultivated and differentiated their EV brand identities as they embrace electric platforms, Tesla Inc was intentionally excluded, since no shift in brand identity was required. The Volkswagen e-Golf was also excluded, despite being the fourth most popular EV in North America in 2020, because it was discontinued at the end of Q3 2020 (Silvestro, 2020). The Volkswagen ID.4 is set to replace 
the e-Golf; however, it will not be publicly available until 2021 so consumer perception cannot yet be accurately measured.

\section{Analysis of Manufacturer Language of EV and ICE Products}

A preliminary quantitative keyword analysis was conducted of manufacturer EV webpages using the online tool Voyant Tools (Sinclair \& Rockwell, 2016). The most used terms, adjectives and descriptors were extracted, forming our keyword data. Simultaneously, a qualitative thematic analysis was also conducted to identify broad themes used by each manufacturer to market EVs online. For comparative purposes, the same process was conducted for each manufacturer's most popular ICE models (Theil, 2021) as measured by total sales -- the Chevrolet Silverado, Nissan Rogue, Audi Q5, and the BMW X3 -- respectively. Since these models encompass the most popular brand offerings, they offer the highest potential for automakers to establish effective brand identities with their consumer base.

Next, using the themes identified in the preliminary evaluation, a confirmatory factor analysis was performed to contextualize the manufacturer keywords obtained by the first stage of research. Phrases that described the vehicles were extracted and listed, with the results sorted and sub-divided into matrix-based tables, identifying primary themes and subthemes for each piece of text. The thematic combinations were then totaled and used holistically, in combination with the identified keywords, to perform the overall evaluation. This identified the key areas of focus for automakers pertaining to their EV/ICE offerings. It also provided a thematic base and a list of terms to compare in the next stage, my analysis of social media discourse. 


\section{Analysis of Public Discourse \& Sentiment Using Twitter}

This next stage began by extracting ("mining") Tweets from Twitter for analysis using the Python programming language. The Python code used in this methodology is a combination of code originally developed by data scientist Jessica Uwoghiren (Uwoghiren, 2020), Martin Beck (Beck, 2020), Yalin Yener (Yener, 2020), and data mining processes developed by JustAnotherArchivist (JustAnotherArchivist, 2018). In combination, the code and functions published by these individuals allows us to aggregate deep insight from large volumes of Twitter data using the Natural Language Toolkit (NLTK). The Natural Language Toolkit utilizes large online reference lexicons to algorithmically perform practical evaluative tasks, such as the removal of common words and the conversion of emojis into text. NLTK also facilitates qualitative data processing functions, such as sentiment and polarity analysis.

The open-source platform Juypter Notebook was used to run the Python script. In order to set up the framework for the processes that were used to collect the data from Twitter, all relevant libraries were imported into our Juypter framework (Appendix A). These libraries load the functions necessary to complete the quantitative and qualitative evaluations described below. Initially, searches were conducted using Twitter's Application Programming Interface (API), but these searches returned limited datasets $(<1000$ Tweets). Due to developer restrictions present in the Twitter API framework, queries are limited to Tweets generated in the past 7 days for nonprofessional accounts. To increase the scope, a domain "scraper" application entitled snscrape, created by software developer JustAnotherArchivist (2018), was used to query data from the 
Twitter domain externally, thus bypassing the API limitations set by Twitter. This code mines relevant Tweets from Twitter's public domain, using a keyword search within a specific date range. This enabled the extraction of a much larger dataset than that available through Twitter's official API framework.

Parameters for our search were set to include all public Tweets made between January 1, 2020 and December 31, 2020. A maximum sample size was set to 10,000 Tweets, retrieving the most recent English language tweets within our specified timeframe, defined by keyword (the car model). This query returns the tweets in continuous json text code format. In order to effectively work with the data, the data was then placed into a data frame using the Python Pandas library. Additionally, the complete data frame was exported as a comma separated values (.csv) file to facilitate the use of analytic tools throughout the remainder of the process.

The data were checked for duplicate entries and Not a Number $(\mathrm{NaN})$ values. These "are special values in DataFrame and NumPy [Number Python] arrays that represent the missing of value in a cell" (Vasile, 2020). These values can cause inaccuracies in the data through "change of some metrics [such] as mean or median values," as well as cause problems with analysis because many “[scikit-learn] implemented algorithms can’t perform on datasets that have such values" (Vasile, 2020).

Once the data was ready to be processed, the tweets were first filtered to remove punctuation, links, and stop words. Common stop words are defined by the NLTK dictionary and are complemented with user-identified terms that could clutter the dataset. These include words 
such as the name of the auto manufacturer, the model's name, basic colors and any other words that are likely to appear in high frequency, but do not lend meaningful insight. For example, the word available was included due to its high frequency. This could be because the data frame was limited to 2020, the year of the COVID-19 global pandemic, and many Twitter users were discussing supply shortages affected by global trade disruptions. Due to its high level of use across all manufacturer results, it was manually removed through the stop word function (Figure 1). Due to the power of the NLTK process, emojis are converted to textual format using the Emot Python library and can be included in sentiment analysis. Adjectives are also extracted and categorized separately at this stage using the NLTK. To accurately process the text and remove duplicate terms, all text was converted to lowercase.

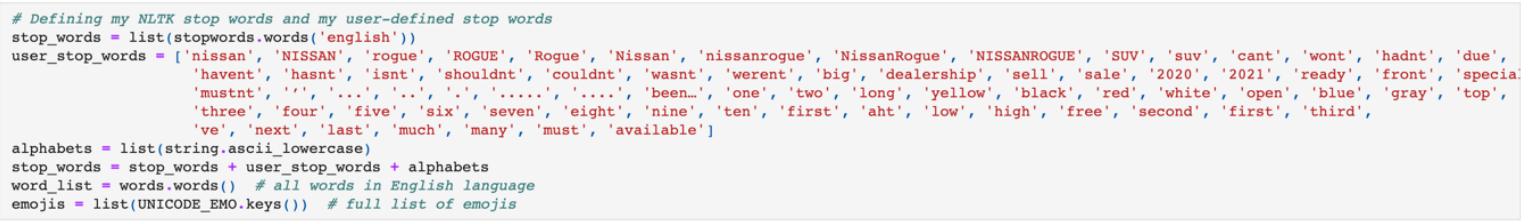

Figure 1. Defining NLTK custom stop words

To streamline the dataset, all words were reduced to their base form using the preprocess NLTK function. There are numerous tools available to complete this task, and for this project the Lemmatizer function was used. To visualize the resulting data frame and assist in initial analysis, a word cloud was then generated. To accomplish this, the column "Tweet_Adjectives" was extracted into a continuous line of text. A cloud frame was then imported, and visual parameters were assigned using the Matplotlib function. The resulting word clouds can be seen in the following analysis and provided a starting point to visualize the collected data. 
The next stage of analysis involved breaking the collection of adjectives identified in each tweet into a numerical list to evaluate the frequency of specific terms. The results of this list were then visualized using the Plotly Python graphing library. Results are displayed as a bar graph list, as well in pie chart format (Appendix J).

To better understand how Twitter users are using the terms outlined in the dataset, a sentiment analysis was then conducted. The Python library TextBlob uses machine learning and extensive reference lexicons to complete natural language processing tasks, in this case assigning polarity values to each piece of text, ranging from -1 (Negative), 0 (Neutral) and +1 (Positive) (Appendix A). This process results in a numerical output, as well as a bar graph representing the data set (SI 1).

Now that the most frequently used words have been identified and overall sentiment has been evaluated, the context of individual terms was further explored through the use of bigrams and trigrams. This process identified the most frequently occurring word combinations within the dataset. All words had already been reduced to their base form from the lemmatization process and terms have been tokenized for better categorization. The results of this process can be seen below, with the Tweets organized into 10 specified columns.

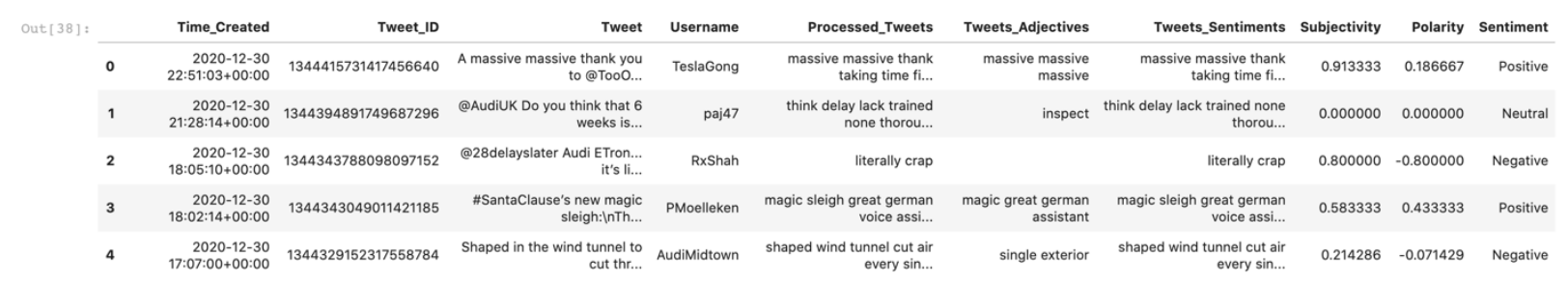

Figure 2. Information extracted from Twitter data 
The data was then separated to find the 10 most used words found in the specified Twitter corpus (Table 1). This data frame was then used to extract ngrams, commonly co-occurring words, from the "Tweet_Adjectives" column. This established the list of most used bigrams present in the corpus along with their rate of occurrence (Table 8, Table 10). The same process was then completed to define the most used trigrams (Table 9, Table 11).

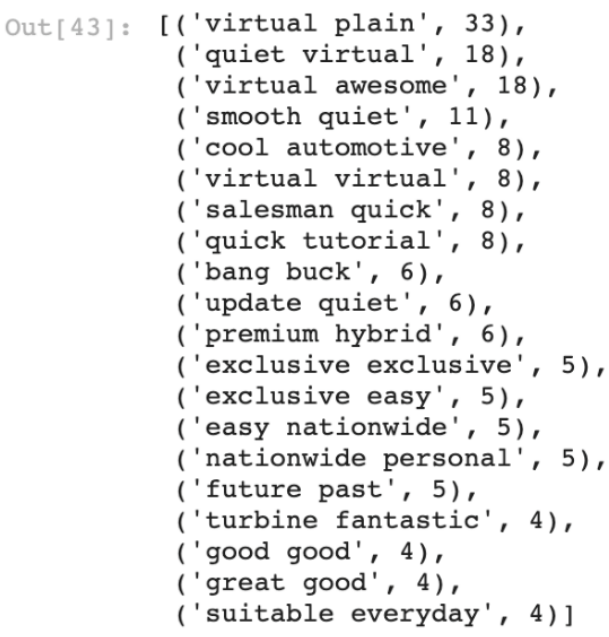

Figure 3. Raw bigrams data from Audi e-tron

This data was then compiled to form an overall dataset for all EV and ICE models. The resulting aggregate data enables us to determine the overall sentiment of each tweet group, as well as the most common keywords and keyword combinations used by Twitter users. 


\section{Analysis}

\section{Quantitative \& Qualitative Evaluation of Automaker Product Descriptions}

When viewing the manufacturer analysis results, it is apparent that despite automakers pursuing decidedly different EV marketing strategies, many maintain several overlapping areas of focus. Keyword adjectives sourced from webpages found commonalities both between $\mathrm{EV} / \mathrm{ICE}$ products from the same manufacturer, as well as between EV/ICE products between manufactures (Table 1).

Table 1. Most popular descriptive adjectives used by manufacturer per model

\begin{tabular}{rcccc}
\hline $\begin{array}{l}\text { Adjectives } \\
\text { (by popularity) }\end{array}$ & $\begin{array}{c}\text { Chevrolet } \\
\text { Bolt }\end{array}$ & $\begin{array}{c}\text { BMW } \\
\text { i3 }\end{array}$ & $\begin{array}{c}\text { Audi } \\
\text { e-tron }\end{array}$ & $\begin{array}{c}\text { Nissan } \\
\text { Leaf }\end{array}$ \\
\hline 1 & Important & Virtual & European & Tech \\
2 & Compatible & New & New & Range \\
3 & Range & Connected & Range & Intelligent \\
4 & Functionality & Certified & Beauty & Assist \\
5 & Connectivity & Electrifying & Certified & Advanced \\
6 & Current & Luxury & Current & Performance \\
7 & Performance & Designed & Performance & Certified \\
8 & Limited & Effortlessness & Special & Innovative \\
9 & Simple & European & Unique & Green \\
10 & Connected & Experiential & Virtual & Future \\
\hline
\end{tabular}

While the marketing focus for automakers differs between each product, most focus on similar overall themes (Appendix B, C, D, E, F, G, H, I); Driving Experience, Experiential Positioning/Lifestyle Integration, Technology \& Design/ Manufacturing. Most of the attributes discussed in the automaker marketing material are related to one or more of these four thematic categories, for both EV and ICE products respectively. The importance placed on each theme did 
vary between manufacturers. For example, with Audi, Audi Heritage was identified as an additional primary theme (Appendix H). Identified subthemes varied to a greater extent between manufacturers. However, most manufacturers roughly adhered to subthemes of: Style/ Aesthetics, Technology, Accessorizing, Comfort/Convenience, Safety, Family and Performance. Below, I will explore the initial analysis results for each manufacturer:

\section{Chevrolet}

Chevrolet utilized consumer experiential positioning heavily to market both the Bolt EV and Silverado respectively. A total of 7 adjective keywords were used jointly between the models, with the Silverado using more unique keywords specific to model, compared with the Bolt. The Silverado is the only pick-up truck model in our ICE comparison so, understandably, many of the terms used to describe it deviate from other offerings (Appendix F). Descriptive terms for the Silverado include "country", "custom", "rugged", "durable", "hard-working" and "legendary". Additionally, the Silverado has enjoyed unparalleled longevity amongst our selection pool, first launched in 1999 (Graham, 2021), and therefore has well-established brand identity.

A notable effort was made by Chevrolet compared with other manufacturers to use consumer experiential positioning to explain vehicle attributes, especially with respect to the Silverado $($ Silverado $=11$, Bolt $=4)$. An example of this strategy is Chevrolet's heavy emphasis with both model's potential for lifestyle integration. The Silverado, being one of North America's best-selling pick-up trucks (Tulumba, 2021), 
repeatedly emphasizes its capability as a work-oriented vehicle: "built to get the job done right - every time." (Chevrolet, 2021b, para. 1). Many of the highlighted features position the vehicle for professional consumer use, and these are explained in a narrative fashion, such as: "YOU'RE NEVER IN THE DARK. Achieve excellent all-around light coverage when the job starts early or goes late" (Chevrolet, 2021b, para. 12). This experiential positioning assists prospective consumers in visualizing how the specific benefits of the vehicle will impact their lives. As the only pickup truck, a market segment notorious for low fuel efficiency, and the only model in our sample offering an optional diesel powertrain, Fuel Efficiency formed an entirely unique theme for the Silverado.

Chevrolet uses a similar experiential positioning tactic with the Bolt, however, the lower level of brand identity development surrounding this new product is evident when looking at the sample size of descriptive phrases $($ Silverado $=25$, Bolt $=6$ ). Keywords describing the Bolt include: "performance", "dynamic", "premier", "bold" and "practical". It becomes clear when viewing the aggregate data that Chevrolet is still developing the brand identity for this product, especially when compared to the thoroughly developed identity of the Silverado. The keywords used to describe the Bolt are found more commonly throughout the entire EV sample pool, and therefore feel more generic. The marketing for the Bolt also emphasizes lifestyle integration, albeit for a markedly different consumer. The easy-to-use nature of the Bolt features heavily, with "convenience" (3) and "functionality" (20) featured highly amongst the keywords. Performance is not highlighted with the Bolt, with acceleration described as "surprisingly fast" (Chevrolet, 2021a, para. 1). This is less affirmative than the Silverado powertrain, 
described as the "STRONGEST [and] MOST ADVANCED" (Chevrolet, 2021b, para.1) pickup, possessing a "powerfully advanced 6.2L V8" (Chevrolet, 2021b, para. 5). Thematically, the Bolt is targeting consumers seeking an affordable (Appendix B), low maintenance vehicle, capable of city driving and saving money for commuters.

\section{$B M W$}

The all-electric i3 shares many prominent keywords (11) with the X3, despite differences in potential consumer demographics (compact EV v. SUV). Both the i3 and the $\mathrm{X} 3$ are positioned as a means to express individuality, as an "expression of a selfconscious lifestyle" (BMW, 2021a, para. 4), or as a way to "emphasize a sporting character" (BMW, 2021b, para. 4) respectively. Similar to Chevrolet, experiential positioning is used with both models to highlight technology; however, it is used to a greater extent to describe Style/ Aesthetic oriented attributes of the X3 $(\mathrm{X} 3=7, \mathrm{i} 3=2)$, whereas Sustainability $(\mathrm{i} 3=4, \mathrm{X} 3=0$ ) oriented attributes are the focus with the $\mathrm{i} 3$. BMW places more emphasis on the ecological benefits of the i3 than any other manufacturer (i3 =17) (Appendix C).

Sustainability is mentioned within material for all EVs in the sample pool, but the primary sustainability focus are the functional attributes of EV products related to their physical use. Only BMW emphasizes the use of ecologically sustainable practices and materials, not only within the product itself, but throughout the development and manufacturing processes (Appendix C, SI 2). Through this strategy, BMW is the only EV 
manufacturer in the sample pool that specifically attempts to allay conceptual macro concerns about the sustainability of private car ownership, rather than focusing solely on micro-level ecological benefits.

Style/ Aesthetics also form a large component of BMW's marketing strategies with a brand identity of athleticism and sportiness highlighted in material for both vehicles. With regard to Technology, it is predominantly described in conjunction with Driving Experience for both vehicles $(\mathrm{X} 3=7, \mathrm{i} 3=5)$. $\mathrm{BMW}$ also makes an effort to capitalize on its "sporty" brand reputation (Simms \& Trott, 2006) while integrating the i3, with Sport/Sportiness forming a subtheme for the i3 ( $\mathrm{i} 3=10, \mathrm{X} 3=3)$. BMW emphasizes the quick acceleration of the i3's electric powertrain and uses experiential positioning to emphasize its benefits in city driving conditions. This duality explains the benefits of the i3, while simultaneously marketing their product as an exceptional choice for urban consumers. Both the i3 and the X3 feature keywords "European", "luxury" and "exclusive", in keeping with BMWs traditional brand identity (Simms \& Trott, 2006).

\section{Audi}

With both the e-tron and Q5, Style/ Aesthetics factor heavily into how Audi differentiates their products from those of competitors (e-tron $=13, \mathrm{Q} 5=9$ ). This subtheme was present in almost every primary thematic category. Keywords for the etron include: "beauty", "beautiful", and "refined" (Appendix D), while "style", "expressive" and "defined" (Appendix H) are used to describe the Q5. Material for both 
models include the word "boutique" and "exclusive", with the e-tron also referred to as "reserved" and "crafted", and the Q5 as "luxury" (Table 9, 11; Appendix H). This reinforces Audi's strategy to target the premium consumer market with both vehicles, as defined by Evanschitzky \& Woisetschlager (2016). Similar to BMW, Audi is harnessing their existing brand identity to better position and integrate new EV products. The word "European" is used throughout the e-tron marketing material, and Audi Heritage formed a subtheme for both Audi vehicles (e-tron = 5, Q5 =4). Nods to the Audi lineage are primarily used to describe a history of innovation and superior performance for both vehicles.

Technology was highlighted far more with the e-tron $(\mathrm{e}-\operatorname{tron}=22$, Q5 $=4)$ than the Q5, a starker difference than many competitors. Additionally, the discussion of technology spans more thematic categories than the Q5 (e-tron $=4, \mathrm{Q} 5=1)$. In particular, within e-tron marketing material, Technology was used heavily in conjunction with Experiential Positioning/Lifestyle Integration. This is because of the many ways Audi is attempting to position consumers as first adopters of a futuristic technology, those who can "look into the future" (Audi, 2021a, para. 5) and "touch the future" (Audi, 2021a, para. 4), and after driving the e-tron, "wouldn't think about going back to the past." (Audi, 2021a, para. 2). This strategy may prove effective at the moment but will obviously need to evolve as consumers become more familiar with EV technology. Technology was equally mentioned in relation to Driving Experience for both vehicles (the most correlation for the Q5), with the only EV specific technological feature emphasized being the e-tron's “"one pedal' driving style” (Audi, 2021a, para. 2). Other 
technological features related to driving experience, such as the Audi "virtual cockpit" (Audi, 2021a, para. 4), or the "overhead virtual 360" (Audi, 2021a, para. 5) camera, feature in material for both vehicles.

Comfort/Convenience also form prominent subcategories for both vehicles but is aligned much more closely with technology with the e-tron (e-tron $=5, \mathrm{Q} 5=1)$. This is primarily due to a concerted effort by Audi to allay common consumer concerns about range (Gärling \& Thøgersen, 2001), by highlighting "peace of mind” (Audi, 2021a, para. 5) features, such as automatically finding the closest charging stations and an included comprehensive roadside assistance package. Safety is discussed similarly between the two vehicles, highlighting "Audi Pre Sense" (Audi, 2021a, para. 5) safety technology and its ability to "Gain an extra set of eyes on the road" (Audi, 2021a, para. 5) as well as "[helping to] take the stress out of driving" (Audi, 2021b, para. 16) respectively.

Audi's use of similar market positioning for both the e-tron and Q5, as well as their heavy focus on aesthetics and style throughout, suggests Audi's target audience for the e-tron may be similar to that of the Q5. As Audi launches the e-tron lineup, they are attempting to capture consumers who may be looking for a premium vehicle, although not necessarily an EV, but may be swayed by the e-tron's comfort/convenience and/or technological benefits. This is reinforced by Audi's general emphasis on comfort and luxury, rather than sustainable products or practices. 


\section{Nissan}

With regard to the Leaf, Nissan places a strong emphasis on a connected driving experience, as well as "exciting" and "efficient" performance (Appendix E).

Sustainability does not comprise a major theme on its own, with more focus given to the Leaf's potential to integrate into daily tasks. However, ecologically focused keywords were found throughout, with adjectives "green", "sustainable" and "efficient" (Appendix E; SI 2) used to describe various attributes.

Technological benefits are largely communicated using experiential positioning with the Leaf, alongside potential for lifestyle integration. This includes highlighting the Leaf's capacity to stow your bike for "weekend excursions" and is reinforced by an infographic entitled "A Day in the Life of a Nissan Leaf" (Nissan, 2021a, pg. 5), illustrating how the Leaf can improve your daily routine. This differs from the Rogue, where experiential positioning is used evenly across various subthemes. Performance is described as "exciting", "amazing" and possessing "instant acceleration" (Nissan, 2021a, pg. 3), although Nissan places much more emphasis on the Leaf's Comfort/Convenience attributes.

Both the Nissan Leaf and Nissan Rogue highlight industry recognition by listing the awards each vehicle has received. Occupying the same SUV marketspace as the BMW X3 and Audi Q5, the Nissan Rogue is the only vehicle in our sample pool to embrace the "crossover" (Nissan, 2021b, pg.6) moniker. The main theme of the Rogue is 
its "rugged", SUV-like ability to take you anywhere with "maximum confidence" (Nissan, 2021b, pg.3). It differs from the Leaf in that it highlights several family-centric design attributes, most likely because SUVs remain an extremely popular category of vehicle in North America for families (Argon National Laboratory, 2020). Technology is largely marketed around lifestyle integration, phone connectivity and driving experience with the Leaf, whereas it is most thematically connected to Safety with the Rogue (Leaf $=1$, Rogue $=10)$. This could be attributed to the effort of marketing the Rogue as a family vehicle, as well as a tactic to differentiate it in a saturated SUV market (Butters, 2017). Additionally, much like the Bolt and i3, Leaf marketing appears to target city dwellers, most likely because that is currently where most charging infrastructure is located. Furthermore, because of its compact size and range considerations (6 keywords), Leaf owners are practically less likely to travel for extended distances on highways.

Overall, Nissan's marketing efforts of the Rogue are in line with similar offerings for light SUVs in our sample pool, yet focused towards the non-premium market. It appears as though Nissan is attempting to target a similar consumer base with the Leaf as the Chevrolet Bolt: consumers looking for a vehicle that is technologically current, similar to traditional compact offerings, requires minimal effort to integrate into their daily routine and comes at an affordable price point. 


\section{Manufacturer's Overall Branding Efforts}

As seen above, the efforts to integrate EV products, and the extent to which they resemble familiar ICE offerings, varies considerably between manufacturers. BMW and Audi, which both occupy the premium market segment, have placed much more emphasis on sustainability and performance, respectively. This matches their existing brand identities, each highlighting features that go above and beyond daily use and integration. As noted by Bauer et al. (2021), consumers looking at premium offerings are more likely to have a higher net worth and therefore look for vehicles that offer higher brand value in extended attributes, such as style, social status, and high performance (Bauer et al., 2021). These consumers are also willing to pay a premium for ecoconsciousness (Bauer et al., 2020), something that delivers no direct benefit to the consumer.

This differs from consumers of the compact market segment, a space firmly occupied by Nissan's Leaf and Chevrolet's Bolt in our sample pool. Consumers in this marketspace tend to seek functional attributes, such as value, lifestyle integration and practicality (Evanschitzky \& Woisetschlager, 2016). This notion is reinforced by the mentions of government rebates and subsidies for EV ownership, featured much more prominently by Chevrolet.

All EV products prominently included the keyword range. Traditionally a top concern for EV consumers (Gärling \& Thøgersen, 2001), all automakers devote a 
considerable amount of time to allaying these concerns, especially Audi, which promotes exclusive use of its nationwide charging infrastructure with Audi EV ownership. This could be a conceptual reaction to recent US/EU policies that limit gas vehicles (Dugdale, 2018) that have in turn, raised questions about personal car ownership as a whole. BMW, a major German automaker in a country where automobile production is valued at around $€ 498$ billion (Koptyug, 2020) with a strong corporate lobby (Reuters, 2018), could be using this strategy to promote corporate social responsibility while maintaining enthusiasm for private vehicle ownership.

Additionally, all ICE vehicles placed a heavy emphasis on helping drivers increase confidence. This seems to be a common theme used between all manufacturers and suggests that consumers purchasing SUV-style vehicles may value the vehicles branded "ruggedness" but may not yet possess significant off-road experience. Using this knowledge, it appears that manufactures are eager to sell consumers the idea of off-road capability, in contrast to actual real-world off-road performance. This aligns with traditional SUV advertising techniques, as outlined by Chen (2016). Additionally, all manufacturers highlight emotional attributes of vehicles, with material for EVs focusing on intellectual and sensory attributes, whereas pick-up truck/SUV models feature more behavioral attributes, aligning roughly with the effective personality types identified by Moons et al. (2014). Both BMW and Audi use the keyword European in material for EVs more prominently then with ICE vehicles. This allows the manufacturers to capitalize on the relatively high brand recognition of European manufacturers and their respective 
attributes (McCarthy \& Tay, 1989) and associate these attributes with their relatively new EV products.

\section{Identify Public Perception using Twitter}

This stage uses data gathered from Twitter to form a comparative base to evaluate the effectiveness of the manufacturer marketing efforts identified above. Twitter data was collected for each model in our sample pool, with some variation in sample size. Tweets were "mined" within the date range of January 1, 2020 to December 31, 2020 and queried using the model's name. The total sample for all models totaled 60,291 tweets.

Table 2. Number of Unique Tweets in EV Sample per model

\begin{tabular}{lcccc} 
& Bolt & i3 & e-tron & Leaf \\
\hline $\begin{array}{l}\text { Num. of } \\
\text { Tweets }\end{array}$ & 6234 & 5635 & 4027 & 10001 \\
\hline
\end{tabular}

Note: Total EV Sample Size $=25,897$ Tweets

Table 3. Number of Unique Tweets in ICE Sample per model

\begin{tabular}{lcccc}
\hline & Silverado & X3 & Q5 & Rogue \\
\hline $\begin{array}{l}\text { Num. of } \\
\text { Tweets }\end{array}$ & 10001 & 8061 & 6331 & 10001 \\
\hline
\end{tabular}

Note: Total ICE Sample Size $=34,394$ Tweets 


\section{Sentiment Analysis}

To understand the opinions expressed by Twitter users towards these EV/ICE products, a sentiment analysis was then conducted. The sentiment analysis revealed that Twitter users largely speak about EV vehicles in neutral terms, with non-polarizing tweets forming roughly half of all tweets, regardless of EV model (50\%). Of the remaining 50\% expressing a polarized sentiment, $38 \%$ were positive sentiments compared to $12 \%$ with negative sentiment.

Sentiment breakdown was similar for tweets associated with ICE vehicles, with an even higher percentage of neutral Tweets (59\%). Of the remaining $41 \%$ expressing a polarized sentiment, $33 \%$ were positive sentiments compared to $8 \%$ negative sentiments. The difference in the proportion of Tweets expressing a polarized sentiment, 41\% (ICE) compared to 50\% (EV), indicates that Twitter users tweeting about EV vehicles are more likely to hold a polarized viewpoint overall than those users Tweeting about ICE vehicles.

Table 4. Overall EV Sentiment

\begin{tabular}{|c|c|c|c|c|c|c|c|c|c|c|}
\hline & Bolt & $\%$ & i3 & $\%$ & eTron & $\%$ & Leaf & $\%$ & Total & $\%$ \\
\hline Neutral & 3098 & 49.69 & 2924 & 51.88 & 1989 & 49.39 & 4988 & 49.87 & 12999 & 50.19 \\
\hline Positive & 2423 & 38.86 & 2045 & 36.29 & 1583 & 39.29 & 3699 & 36.98 & 9750 & 37.64 \\
\hline Negative & 713 & 11.43 & 666 & 11.81 & 455 & 11.29 & 1314 & 13.13 & 3,148 & 12.15 \\
\hline Total & 6234 & & 5635 & & 4027 & & 10001 & & 25897 & 100 \\
\hline$+:-$ & 3.39 & & 3.07 & & 3.47 & & 2.81 & & 3.09 & \\
\hline
\end{tabular}

Note: Total Sample: 25,897 Tweets 
Table 5. Overall ICE Sentiment

\begin{tabular}{rcccccccccc} 
& Silverado & \% & X3 & \% & Q5 & \% & Rogue & \% & Total & $\%$ \\
\hline Neutral & 5484 & 54.83 & 4923 & 61.07 & 3531 & 55.77 & 6482 & 64.81 & 20420 & 59.37 \\
Positive & 3554 & 35.53 & 2367 & 29.36 & 2300 & 36.32 & 2974 & 29.74 & 11195 & 32.54 \\
Negative & 963 & 9.62 & 771 & 9.56 & 500 & 7.89 & 545 & 5.45 & 2779 & 8.07 \\
\hline Total & 10001 & & 8061 & & 6331 & & 10001 & & 34394 & 100 \\
$+:-$ & 3.69 & & 3.07 & & 4.60 & & 5.45 & & 4.02 & \\
\hline
\end{tabular}

Note: Total Sample: 34,394 Tweets

The ratio of number of positive sentiments to the number of negative sentiments are also more similar within the EV vehicle group than within the ICE vehicle group. Within the EV vehicle group the positive to negative sentiment ratio varies from 2.81 (Nissan Leaf) to 3.48 (Audi e-tron), whereas within the ICE vehicle group this ratio varies from 3.07 (BMW X3) to 5.46 (Nissan Rogue). The positive to negative sentiment ratio of user tweets was therefore greater for ICE vehicles than for EVs. This suggests that users tweeting a polarized opinion about ICE models express stronger opinions, both positive and negative, compared with tweets about EVs.

\section{Keyword Analysis}

A keyword analysis of Tweets was then performed, revealing differences in how each vehicle is talked about on Twitter, with a list created for the top 10 keywords for each vehicle in our sample. 
Table 6. Most Popular Descriptive EV Adjectives Tweeted per model

$\begin{array}{ccccc}\text { Adjectives } & \text { Bolt } & \text { i3 } & \text { eTron } & \text { Leaf } \\ & & & \text { good } & \text { great } \\ 2 & \text { good } & \text { urban } & \text { great } & \text { good } \\ 3 & \text { federal } & \text { good } & \text { virtual } & \text { affordable } \\ 4 & \text { small } & \text { hybrid } & \text { future } & \text { happy } \\ 5 & \text { affordable } & \text { interior } & \text { automotive } & \text { popular } \\ 6 & \text { potential } & \text { leaf } & \text { sustainable } & \text { expensive } \\ 7 & \text { general } & \text { sustainable } & \text { German } & \text { solar } \\ 8 & \text { leaf } & \text { different } & \text { hybrid } & \text { cheap } \\ 9 & \text { current } & \text { nice } & \text { plain } & \text { bad } \\ 10 & \text { cool } & \text { future } & \text { happy } & \text { different }\end{array}$

Note: By popularity (in descending order)

Table 7. Most Popular Descriptive ICE Adjectives Tweeted per model

\begin{tabular}{rcccc} 
Adjectives & Silverado & X3 & Q5 & Rogue \\
\hline 1 & great & insane & interior & social \\
2 & good & great & exterior & loud \\
3 & hot & hybrid & hybrid & great \\
4 & old & automatic & premium & welcome \\
5 & sierra & interior & great & good \\
6 & interior & electric & electric & awd \\
7 & nice & good & automatic & interior \\
8 & pickup & follow & good & clean \\
9 & manual & beauty & manual & drive \\
10 & welcome & happy & metal & nice \\
\hline
\end{tabular}

Note: By popularity (in descending order)

The adjective good was by far the most popular descriptor of all EVs in the sample, used a total of 832 times. It was the most popular keyword for the Chevrolet Bolt and Audi eTron, and the second most popular for the BMW i3 and Nissan Leaf (whose most popular keywords were "urban" and "great" respectively). The lists for Bolt and i3 also contained the keyword "leaf", an 
indicator that consumers are often discussing compact EVs together. This is not, however, reciprocated by users tweeting about the Nissan Leaf. The most frequently used keyword combinations, bigrams and trigrams (see Table 8, 9 10,11), were also extracted at this stage from the Twitter data. The Twitter analysis results for each manufacturer can be seen below:

\section{Chevrolet}
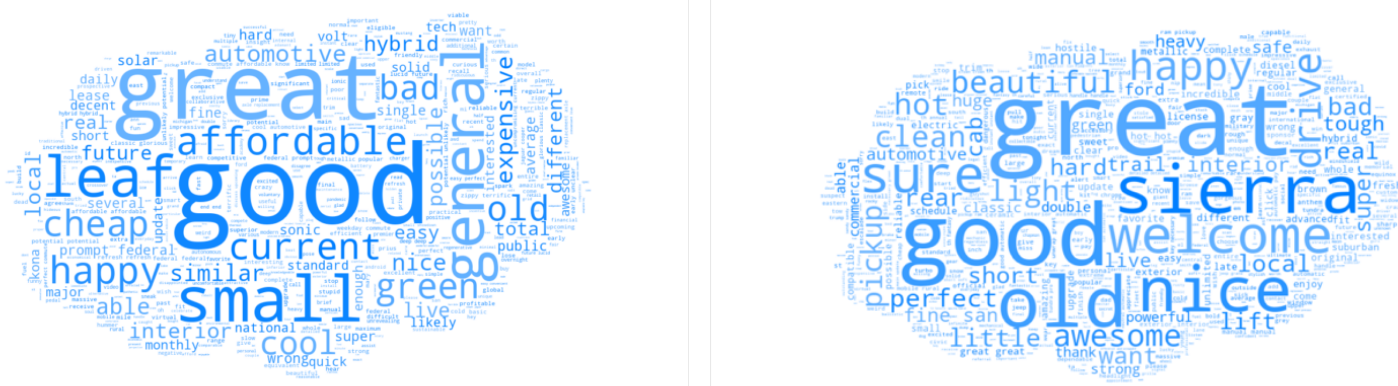

Figure 4. Most Common Keywords: Bolt (L) \& Silverado (R)

Viewing bigram and trigram keyword combinations, it can be seen that "prompt federal" occupies the most common combination for Chevrolet. This contextualizes its high occurrence rate on the keyword list, suggesting it is in fact related to the many government mandates (especially in the US) currently promoting EV ownership (Biden, 2021; State of California, 2021). This reference doesn't appear with any other EV, and Chevrolet was the only manufacturer to highlight the potential for government subsidies in their marketing material. This suggests that Chevrolet is successfully capitalizing on consumer interest spurred by these new mandates, and this interest is being reflected in public Twitter discourse. Perceptions of better-than-expected performance are also echoed among Twitter users with the Bolt being described as possessing "unlikely 
potential", similar to Chevrolet's description of the Bolt as "surprisingly fast"—a subtle allusion to Usain Bolt. Along these same lines, Chevrolet's emphasis on quick acceleration and city performance matches a common theme among Twitter users, referring to the Bolt as "zippy". The manufacturer's emphasis on affordability is also reflected in discourse, mentioned twice in keyword combinations. The range estimates given by Chevrolet, such as "all you need for your daily routine plus a few stops" (Chevrolet, 2021a, para. 3), matches Twitter sentiment, with the Bolt mentioned alongside: "weekday commute affordable", "easy perfect commute" and "weekday commute range". Additionally, Twitter data also revealed "replacement axle", as a common bigram. This is a documented issue amongst Bolt owners (Ruffo, 2020), and is significant enough to cause repeated mentions within the Twitter community.

As mentioned previously, the Silverado benefits from extensive market longevity in the long-standing and established pickup truck market. As such, keyword combinations for the Silverado prominently feature four competitors: the Dodge Ram, the GMC Sierra, the Toyota Tundra, as well as SUV, the Jeep Grand Cherokee. This is the most mentions of competitor products within the ICE sample, which mirrors the Bolt, with the most competitor mentions in our EV sample group. This suggests that Twitter users' tweet about Chevrolet products in a comparative sense more so than any other manufacturer. The Silverado was also described as "awesome affordable repairable", in keeping with the manufacturer descriptors of "durable", "tough" and "strong". 


\section{BMW}
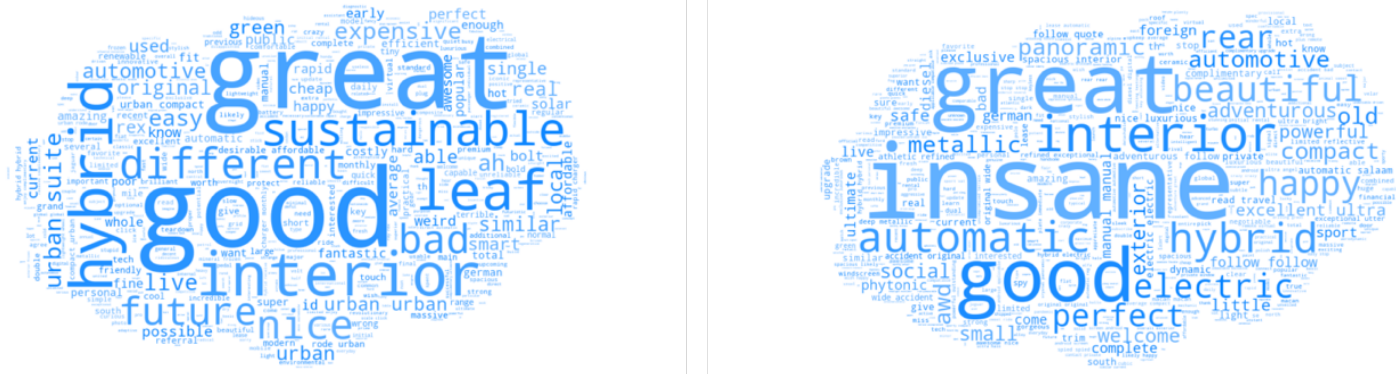

Figure 5. Most Common Keywords: i3 (L) \& X3 (R)

The most noticeable i3 keyword trend is the word urban, which appears a total of 9 times within the bigrams/trigrams, and 4 times in the top 3 most used bigram/ trigram combinations. Its popularity as the most used i3 adjective is contextualized alongside keywords such as "ultimate", "limited", "enjoy" and "compact". The i3s heavy association with urban living could partially be due to its compact size and the vehicle's comparatively low range capability of $246 \mathrm{~km}$ (BMW, 2021a). The brand identity cultivated by BMW showcases the i3s unique design, which is positively reflected on Twitter as "unmistakable influential distinctive". Marketing to premium consumers in urban environments is especially important for the i3s success because the i3's starting price places it in the same market segment as the Tesla Model 3, which possesses almost double the range with a capability of $568 \mathrm{~km}$ (Tesla, 2021).

Positioning the model for urban consumers is also evident by BMWs highlighting the i3's ability to accelerate "from 0 to 100 [...] in just 7.3 seconds" (BMW, 2021a, para. 4) making it "thrillingly agile" (BMW, 2021a, para. 3). The performance is also 
described by BMW as "powerful up to a maximum speed of $160 \mathrm{~km} / \mathrm{h}$ ” (BMW, 2021a, para. 1), a low top speed unlikely to appeal to highway commuters. Additionally, the limited range places of the BMW behind other EV options in the same premium market segment (Evanschitzky \& Woisetschlager, 2016) and far behind most gas equivalent models, making it an unappealing choice for those with long commutes, or who live outside of major urban centers. The range can be extended by adding a supplementary gasoline generator (BMW, 2021a), which is likely why "hybrid" appears as a top keyword overall. This also contextualizes the bigram "ray rex", which references circulation of a Daily Mail article by automotive reviewer Ray Massey ${ }^{1}$. In the article, Massy reviews the i3's performance, in particular its gasoline range extender $(R E x)$, illustrating that range remains a primary focal point for all EV discussion. However, there are multiple hybrid options with higher performance and lower cost (U.S. Department of Energy, 2021) and the option of adding a gasoline engine is unlikely to captivate to sustainability focused consumers.

BMW places a heavy focus on performance for both the i3 and X3, however, more attention is paid to Driving Experience for the X3 in manufacturer materials. This emphasis is not reflected in X3 Twitter discourse. When looking at the keywords for the X3 compared to the $\mathrm{i}$, the word urban does not feature, reinforcing the notion that BMW has made a concerted effort to market the i3 to consumers based in cities. Experiential positioning was used by BMW to highlight the X3's Aesthetics/ Style (X3 = 7), and this focus appears to have carried over to public discourse. Additionally, experiential

\footnotetext{
${ }^{1}$ https://www.dailymail.co.uk/motoring/article-2508877/Truly-electric-Ray-Massey-tests-BMW-I3-REX-RangeExtender.html
} 
positioning was used by BMW to highlight the i3's sustainability, which is also reflected in the most popular Twitter keywords for that model. This suggests that BMW has successfully used experiential positioning to convey key features of both vehicles to consumers, sustainability for the $\mathrm{i} 3$, and premium aesthetics for the $\mathrm{X} 3$. The trigrams for the $\mathrm{X} 3$ also reveal an association with the Porsche Macan, a more expensive SUV (BMW, 2021b; Porsche, 2021), suggesting that BMW has achieved a level of success with brand value alignment with premium consumers. This notion is reinforced by the popularity of keywords "luxurious", "athletic", "refined" and "exceptional".

\section{Audi}
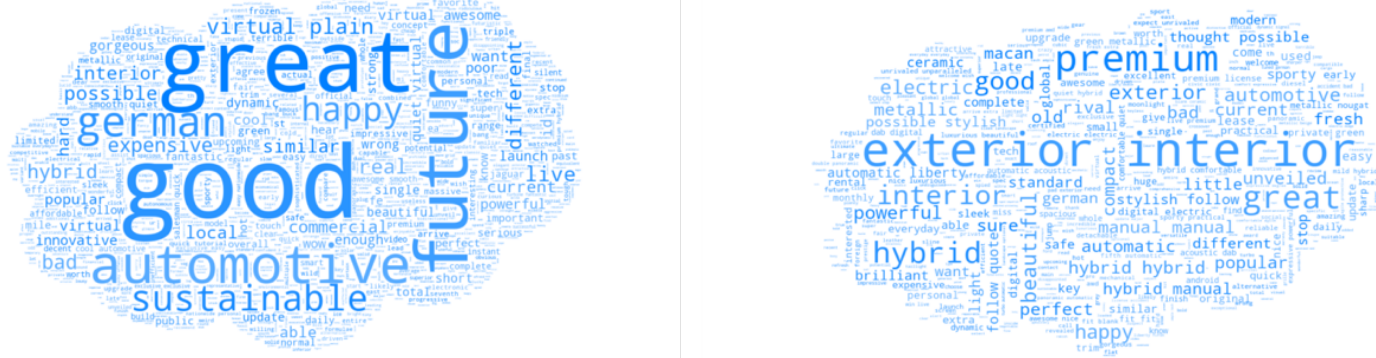

Figure 6. Most Common Keywords: e-tron (L) \& Q5 (R)

Audi's cultivated association of their e-tron model with the word "virtual", which features heavily throughout their manufacturer material, has successfully been embraced within public discussion, featured 10 times in the most popular bigrams/trigrams. Audi has also successfully defined the e-tron brand as a premium product, described in Twitter discussions as "exclusive" and "premium". Audi's branding focus on Style/ Aesthetic attributes is also evident with aesthetics being the focus of 3 popular keyword 
combinations (Table 9). Audi's panoramic roof, as well as the EVs interior experience also form a theme in Twitter discussions, described as a "comfortable sophisticated interior" and "quiet".

The other major theme within Twitter e-tron discourse is the Electrify Canada network, "the fastest public charging network in Canada" (Electrify Canada, 2021, para. 1). In collaborative promotion with Audi, "e-tron owners will receive two years of complimentary 30-minute charging sessions on the Electrify Canada High Powered charging network" (Audi, 2021a). This offer has successfully generated public interest, with Twitter users referencing the deal, as seen by top trigrams "exclusive easy nationwide" and "easy nationwide personal" (Table 9). This is a particularly important focus for Audi, because despite offering a competitive range, the e-tron also delivers the highest cost per km of any EV in the sample pool (U.S. Department of Energy, 2021).

Discourse surrounding the Q5 is in keeping with Audi's main brand focus on stylish aesthetics and premium features. This can be seen by the high frequency of the keyword "premium", as well as the use of descriptive trigrams "awesome nice luxurious" and "nice luxurious beautiful" (Table 11). Audi focus on superior cabin acoustics is also reflected by Twitter users, as is Audi's highlight of the Q5's large panoramic moonroof. Audi's focus on a large moonroof, as well as a comfortable interior, is also visible in discourse surrounding the e-tron, which Twitter users describe as "comfortable" and "sophisticated" (Table 9). 


\section{Nissan}
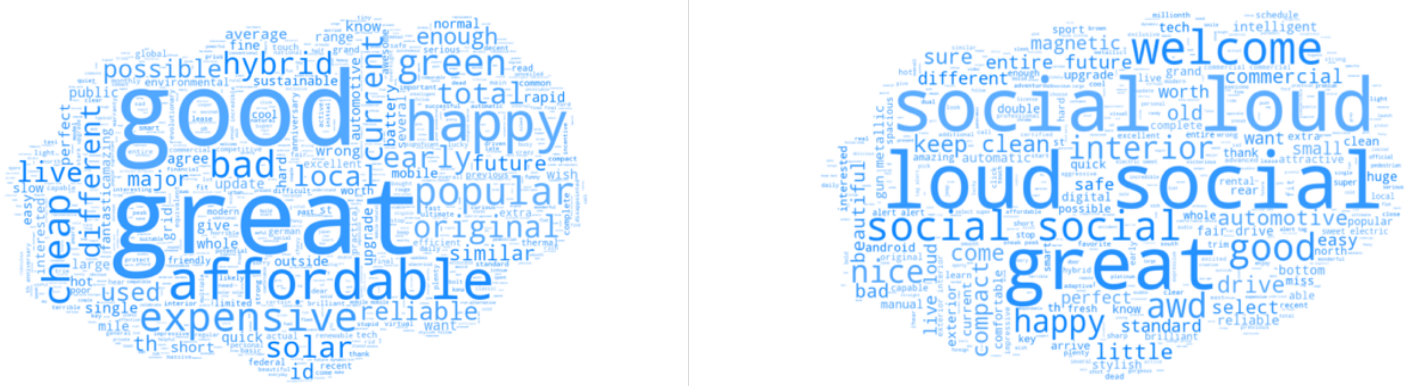

Figure 7. Most Common Keywords: Leaf (L) \& Rogue (R)

Nissans branding efforts appear congruent between marketing material and public discourse. Many keywords are directly carried over from the manufacturer, such as "future", “intelligent", "innovative", “tech", "sleek" and "distinctive”. Despite not being heavily focused on in marketing material, users frequently commented positively on the Leaf's physical appearance, describing its sweeping roof as "sharp" and "distinctive", and it's exterior as "dynamic" and "innovative". The focus on the Leaf's aesthetics aligns more with users tweeting about premium offerings, such as the i3 or e-tron, then with EVs sharing the same market segment, such as the Bolt.

"Solar solar" also appears as a common bigram for the Leaf. This can be attributed to the 2015 Nissan Leaf, which featured a "photovoltaic solar panel spoiler on SL models, which [supported] charging of the 12-volt battery for vehicle accessories" (Krivevski, 2014, para. 10), despite it acting as more of a signifier of the vehicle's greenness rather than providing any significant practical benefit. This, along with the affordable price of used Leafs, has also led to online interest in completely sustainable 
solutions, including trickle-charging your EV with self-mounted solar panels. The Leaf's sustainability attributes are mentioned by Twitter users more than any other EV model, despite BMW having a higher focus on this aspect in their marketing material. This demonstrates a clear association within the Twitter community between the Nissan Leaf and sustainability/ sustainable practices. Twitter users also describe the Leaf as a "good dependable compact", emphasizing the Leaf's overall marketing theme while also highlighting Nissan's strategic brand value alignment success.

Nissan's efforts to market the Rogue to those with an active lifestyle is apparent, with repeated Twitter references to "sport" and “adventure”. Nissan's highlighting of industry awards is also notable and is directly discussed by Twitter users. While Nissan's efforts to brand the Rogue as a family vehicle are not immediately apparent in Twitter discourse, attributes that offer similar brand value are mentioned, such as its "comfortable compact" nature, its "spacious interior" and its "maximum cargo" potential. The Rogue's identity as an SUV is also readily apparent, with users describing the vehicle as "awd" (all-wheel drive), "strong", "adventurous" and "sport[y]". Unlike BMW and Audi, Nissan's brand alignment focuses less on premium features and more on functionality, in keeping with Nissan's market segmentation (Evanschitzky \& Woisetschlager, 2016). 


\section{Conclusion}

The established nature of ICE brand identities, as seen through their flagship models, can be seen through each manufacturer's highly developed advertising language which carefully aligns their ICE product with their target market. Comparatively, EV models are marketed more generally as electric alternatives, with less specific sub-market differentiation. Overall, there were more subthemes for ICE vehicles, indicating a greater diversity in the way manufacturers have cultivated brand identities surrounding each model. EV marketing material largely focused on similar areas of interest, most specifically the incorporation of electric technology, suggesting manufacturers are still trying to conceptually sell the idea of an EV to consumers, rather than their EV.

Descriptors, however, are less dynamic with ICE vehicles in general. This illustrates the concerted branding effort manufacturers are making to foster strong brand identities within their respective EV lineups. Research, such as the work of Chen (2016) and Moons et al. (2014), demonstrates the value of brand positioning and brand value alignment within the automotive industry. EVs have the potential to act as "signifiers of technology" (Chen, 2016, pg. 17), and in keeping with this notion, all manufacturers have made notable efforts to represent their EVs as futuristic. All maintain a heavy focus on the benefits provided by integrated technological attributes, such as convenience (Bolt), advanced safety features (Audi), driving experience (BMW) and even autonomous driving capabilities (Leaf). 
Individual approaches continue to vary by manufacturer, but efforts to integrate the electric products using their prior brand positioning are evident. For example, "premium" was heavily used within both Audi sample groups, which aligns the EV with Audi's traditional overall brand values and market segment. Tweets refer to the e-tron as "German", which is consistent with Audi's aggressive marketing of the brand's "European" heritage. This "European" branding was also used with BMW's i3, but conversely, was not reflected by sample tweets. This could be indicative of the salience of Audi's strategy of focusing on style and aesthetics, which due to its visual nature, may be more conducive to social media posts then BMWs greater focus on sustainability. The heavy use of the keyword "virtual" by Audi was also present within sample tweets. This suggests that despite the e-tron's brand identity appearing less developed and less EVspecific compared with other vehicles in our sample, Audi's chosen areas of focus and cultivated lexicons are effectively translated into consumer discourse.

The i3 and Leaf are noted as "different" and are pitched as a medium for consumers to convey their individual, ecologically conscientious, identities. This message from manufacturers acknowledges consumer wariness about EVs, and similar to that pitched by Toyota when launching the Prius (Allison, 2003), their products may offer additional social appeal for those seeking to make a statement about their environmental beliefs.

A general shift in the automotive industry towards electrified powertrains is evident, with the keyword "hybrid" appearing in searches for the i3, e-tron, Leaf, X3, and 
Q5. This is most likely due to the hybrid powertrain options available for e-tron, X3 and Q5, and the semi-hybrid nature of the i3's range extender option. The Leaf is a fully electric vehicle, but other hybrid options are available from Nissan. The popularity of these associations should be noted, as even consumers discussing ICE vehicles are now also frequently speaking about electric powertrain options.

The full-torque capability of electric powertrains is highlighted in all EV manufacturer marketing materials, and often coincides with urban centric experiential positioning, especially in the case of BMW. This is an example of a functional benefit electric powertrains possess over their ICE counterparts that is being successfully conveyed to consumers, as evidenced by keywords such as "zippy" in Twitter discourse. Referred to as "one-pedal driving" by several manufacturers, due to the slow-down effect of the EV regenerative braking system, represents one of the first major EV specific features that manufactures are choosing to highlight. The popularity of this feature also reinforces the notion that popular EV features are often focused on the practical benefits for individual users beyond sustainability. Similarly, premium manufacturers BMW and Audi placed a strong emphasis on a luxurious cabin experience, which is also mirrored in Twitter discussions.

Nissan's brand emphasis on lifestyle integration is evident with the prominence of the term "social", "happy" and "welcome". As well as being described by Twitter users as "popular", the Leaf is the only EV in the sample that repeatedly is mentioned alongside similar models, while also forming the largest EV tweet sample group. 
Additionally, Twitter users often post comparatively, with searches for the Bolt and the i3 returning reference to the Leaf, and the $\mathrm{X} 3$ and Silverado referencing vehicles in the same market segment. This indicates that Twitter may provide a useful source of information for those seeking to compare specific models of car, or to confirm public perception of a model's market segment.

Affordability formed a prominent theme among all EV models. This is reflective of the high market price of EVs, usually more expensive than comparable ICE models, with EV purchasers tending to have higher than average incomes (Bauer et al., 2021). This focus is highlighted more prominently in the Twitter discourse surrounding the Bolt and Leaf, which are the two non-premium, less-expensive models. Chevrolet was the only manufacturer to prominently feature the eligibility for federal purchasing credits with their EV, and this was discussed by Twitter users. This suggests that focusing on and promoting affordable purchase options and government rebates is especially effective for EVs in the non-premium market.

As new technology develops and the cost for electric hardware drops, further exploration of benefits offered by EV-only models and the promotion of these benefits, such as advanced autonomous driving/fueling capabilities, will help captivate consumer interest. Range still poses a significant concern for consumers and may only subside after significant global improvements to electric charging infrastructure. In the meantime, competitive cost-value propositions, such as those offered through government rebates, 
may prove effective at allaying these concerns, as evidenced through Twitter discourse surrounding the Bolt.

While individual manufacturer approaches to EV brand integration vary significantly, each has illuminated several key areas of success when integrating EVs into their respective product portfolios. The findings indicate that electric powertrains are gaining significant traction and are being actively discussed in both EV and non-EV specific terms. Thus far, manufacturers have had some success with brand value alignment, notably Nissan and Audi, and appropriate market segmentation of their EVs. Moving forward, it is imperative for manufacturers to cultivate and promote EV brand identities that go beyond sustainability focused attributes, since sustainability alone may not be enough to hold consumer attention. Further brand development focusing on nonsustainable attributes will ultimately determine how manufacturers distinguish their products after the widespread integration of EVs into the consumer market over the coming decade. Regardless of environmental benefit, EVs will form a significant portion of the automotive landscape for years to come. With fairly new product lines, it is important for manufacturers to quickly develop and establish unique brand identities that differentiate their products. Taking notes from Tesla's success, manufacturers need to focus on not only conceptually selling consumers an EV, they need to sell us their EV. 


\section{Considerations \& Limitations}

Due to the limits of this study's search parameters, such as timeframe, searches for individual models returned different results. As noted in the research, the sample size for the Nissan Leaf was over double that of the Audi e-tron, and this should be considered when interpreting the results. The reason for variance could be due to many factors, including a more dynamic manufacturer social media presence, divergence of market demographics vs. Twitter-specific user demographics, as well as Twitter platform specific considerations. Additional studies would be required to fully understand the intricacies of this aspect. Twitter enables users to post images within their Tweets, and these images, videos or linked files were not evaluated as part of this study. Likewise, retweets, likes, influence metrics and other interactivity between Twitter users was also not measured. Due to language barriers, only tweets in English were evaluated in this study and thus results should only be considered representative of English language Twitter users.

Several of the models in this study also have multiple sub-variants (known as trim levels). With the e-tron, Audi didn't launch the full lineup until 2021, whereas during our sample data, the e-tron was offered as the e-tron Sportback. Due to the common way consumers describe both vehicles, it is unlikely this had a significant effect on the results but should nonetheless be noted. Since this study focused on the overall impression of EV branding efforts at the manufacturer level, differentiation between sub models was not necessary. Determining the use, and frequency, of custom stop words also presented a challenge, as you are filtering your dataset and was done sparingly. While these keywords are largely similar 
within the context of this study, such as basic colors, the manufacturer name (and variants) and model name (and variants), they do vary slightly between models.

\section{Contributions and Future Research}

This study identified several areas of consideration when marketing and cultivating a brand identity for a new EV. The advertising landscape has dramatically changed since the launch of the first EV in the 1970s, particularly following the rise of social media (Spurgeon, 2007). Social media has become a driving force and metric for gauging consumer interest, engagement and perception of new products (Baum et al., 2019). Unique considerations must be given to each media platform in order for a brand proposition to be successful. Because this study focused solely on Twitter, further studies are needed to determine the effectiveness of EV marketing across the social media landscape. Alongside this shift in advertising and media consumption, there is also a shift in North American car culture away from the hyper-masculine, gas-hungry vehicles of the previous century. Manufacturers are rebranding, moving towards a more tech-centric, convenience oriented, and energy-efficient vehicle, embodied by EVs. How this shift in car culture will influence future EV branding remains to be seen and represents a potential future line of research.

Additional studies are needed to see how the marketing efforts of Tesla/ Polestar/ EVonly companies compare with traditional automakers. Although this study focused on brand integration of $\mathrm{EV}$ products within traditional automotive companies, many parallel challenges were faced by Tesla Inc when launching their all-EV automotive brand. Tesla Inc's notable 
branding success (Hardman et al., 2015) cannot be overlooked and can provide a framework for automotive companies to use with their own EV products. The existing influence Tesla Inc has already had on the manufacturers in our sample would require a separate study to quantify.

The 2020 COVID-19 pandemic caused large disruptions, both in businesses and lifestyle, around the world. While any effect on our sample is not readily apparent, there are many reasons why this may have affected our results. Google Trends data for 2020 shows a consistent drop in Google searches for each EV model in Q2 2020 (Google Trends, 2021), roughly aligning with the beginning of strict global lockdown policies. The drop in internet searches when compared to ICE models, was not as dramatic and rose towards the end of Q4 for most models. A separate study would be required to understand any effect the global pandemic had on automotive discourse, and what specific changes are evident post-pandemic between EVs and ICE models. 
Table 8. Most popular EV bigrams from Twitter sample by model

\begin{tabular}{|c|c|c|c|}
\hline Chevrolet Bolt & BMW i3 & Audi eTron & Nissan Leaf \\
\hline 'prompt federal' (29) & 'urban suite' (40) & ‘virtual plain’ (33) & 'th anniversary' (14) \\
\hline 'unlikely potential' (16) & 'urban compact' (19) & 'quiet virtual' (18) & 'stark upgrade' (14) \\
\hline 'weekday commute' (15) & ‘desirable affordable’ (17) & 'virtual awesome' (18) & 'great great' (12) \\
\hline 'good good' (14), & 'rode urban' (15), & 'smooth quiet' (11) & 'stylish follow' (12) \\
\hline 'classic glorious' (14) & 'rapid charger' (10) & 'cool automotive' (8) & 'great good' (9) \\
\hline 'lucid future' (13) & 'charger monthly' (10) & 'virtual virtual' (8) & 'popular significant' (9) \\
\hline 'cool automotive' (12) & ‘mineral frozen' (7) & ‘salesman quick’ (8) & 'future dynamic' (8) \\
\hline 'zippy terrific' (9) & 'great monthly' (6) & 'quick tutorial' (8) & 'good good' (8) \\
\hline 'early unclear' (9) & 'ray rex’ (6) & 'bang buck' (6) & 'mobile natural' (8) \\
\hline ‘commute affordable' (7) & 'lightweight wheel' (6) & 'update quiet' (6) & 'intelligent impressive' (8) \\
\hline $\begin{array}{l}\text { 'uncompromising current' } \\
\text { (7) }\end{array}$ & 'ride urban' (6) & 'premium hybrid' (6) & 'different different' (8) \\
\hline 'perfect commute' (7) & 'future urban' (6) & 'exclusive exclusive' (5) & 'solar solar' (7) \\
\hline ‘jaguar cooper’ (7) & 'ultimate urban' (5) & 'exclusive easy’ (5) & 'exterior dynamic' (7) \\
\hline 'replacement axle' (7) & 'urban limited' (5) & 'easy nationwide’ (5) & 'sleek aerodynamic' (7) \\
\hline 'easy perfect' (6) & 'limited enjoy' (5) & 'nationwide personal' (5) & 'aerodynamic contemporary' (7) \\
\hline 'great good' (5) & 'enjoy complimentary ‘ (5) & ' future past' (5) & 'distinctive roof' (7) \\
\hline 'small showdown’ (5) & 'hybrid hybrid' (5) & 'turbine fantastic' (4) & 'virtual great' (6) \\
\hline 'discuss upcoming' (5) & 'initial rental' (5) & 'good good' (4) & 'rapid charger' (6) \\
\hline 'general global' (4) & 'direct automatic' (5) & 'great good' (4) & 'charger monthly' (6) \\
\hline 'good bad' (4) & 'frozen interior' (5) & 'suitable everyday' (4) & 'great acceleration' (6) \\
\hline
\end{tabular}

Notes: Frequency in brackets (in descending order by popularity) 
Table 9. Most popular EV trigrams from Twitter sample by model

\begin{tabular}{|c|c|c|c|}
\hline Chevrolet Bolt & BMW i3 & Audi eTron & Nissan Leaf \\
\hline $\begin{array}{l}\text { 'weekday commute } \\
\text { affordable' (7) }\end{array}$ & $\begin{array}{l}\text { 'rapid charger } \\
\text { monthly' (10) }\end{array}$ & $\begin{array}{l}\text { 'quiet virtual } \\
\text { awesome' (18) }\end{array}$ & $\begin{array}{l}\text { 'sleek aerodynamic } \\
\text { contemporary’ (7) }\end{array}$ \\
\hline ‘easy perfect commute’ (4) & 'ultimate urban limited' (5) & 'smooth quiet virtual' (11) & 'rapid charger monthly' (6) \\
\hline 'good good good' (3) & $\begin{array}{l}\text { 'limited enjoy } \\
\text { complimentary' (5) }\end{array}$ & 'update quiet virtual' (6) & $\begin{array}{c}\text { 'acceleration ecological } \\
\text { exterior' }(6)\end{array}$ \\
\hline $\begin{array}{l}\text { 'private resident } \\
\text { financial' (3) }\end{array}$ & $\begin{array}{l}\text { 'hybrid receive } \\
\text { complimentary' (5), }\end{array}$ & $\begin{array}{c}\text { 'exclusive exclusive } \\
\text { easy' (5) }\end{array}$ & $\begin{array}{l}\text { 'ecological exterior } \\
\text { dynamic' (6) }\end{array}$ \\
\hline 'good plenty amazing' (3) & $\begin{array}{l}\text { 'frozen interior } \\
\text { automatic' (4) }\end{array}$ & $\begin{array}{l}\text { 'famous innovative } \\
\text { powerful' (3) }\end{array}$ & 'sharp distinctive roof' (6) \\
\hline $\begin{array}{l}\text { 'general unveiled } \\
\text { driverless' (3) }\end{array}$ & $\begin{array}{l}\text { 'metallic scale } \\
\text { click' (4) }\end{array}$ & $\begin{array}{c}\text { 'innovative powerful } \\
\text { efficient' (3) }\end{array}$ & 'distinctive roof smart' (6) \\
\hline $\begin{array}{l}\text { 'unveiled driverless } \\
\text { different' (3) }\end{array}$ & $\begin{array}{l}\text { 'know touch } \\
\text { live' (4) }\end{array}$ & 'future past frozen' (3) & 'mobile natural extreme' (4) \\
\hline $\begin{array}{l}\text { 'weekday commute } \\
\text { range' }(2)\end{array}$ & $\begin{array}{l}\text { 'referral great } \\
\text { monthly' (3) }\end{array}$ & $\begin{array}{l}\text { 'past frozen sustainable' } \\
\text { (3) }\end{array}$ & 'decided large north' (4) \\
\hline $\begin{array}{l}\text { 'potential voluntary } \\
\text { potential' }(2)\end{array}$ & ‘idiom represent future' (3) & $\begin{array}{l}\text { 'styling metallic } \\
\text { panoramic' (2) }\end{array}$ & 'original fifth classic' (3) \\
\hline 'upcoming stray current' (2) & ‘unveil urban suite’ (3) & $\begin{array}{l}\text { 'adventure innovative } \\
\text { collective' (2) }\end{array}$ & 'stop hybrid great' (3) \\
\hline ‘want live gotten’ (2) & ‘urban suite passenger’ (3) & $\begin{array}{c}\text { 'launch panoramic } \\
\text { virtual' (2) }\end{array}$ & 'hybrid great good' (3) \\
\hline 'live gotten ceramic’ (2) & $\begin{array}{l}\text { 'suite passenger } \\
\text { individual' (3) }\end{array}$ & $\begin{array}{l}\text { 'panoramic virtual } \\
\text { metallic' (2) }\end{array}$ & 'monthly rental personal' (3) \\
\hline 'gotten ceramic hot' (2) & $\begin{array}{l}\text { 'passenger individual } \\
\text { standard' (3) }\end{array}$ & ‘combine rapid rapid’ (2) & 'rental personal monthly' (3) \\
\hline 'worth academy clear' (2) & 'spacious fresh dual' (2) & $\begin{array}{c}\text { 'comfortable sophisticated } \\
\text { interior' }(2)\end{array}$ & 'pep arsenal modest' (3) \\
\hline
\end{tabular}

Notes: Frequency in brackets (descending order) 
Table 10. Most popular ICE bigrams from Twitter sample by model

\begin{tabular}{|c|c|c|c|}
\hline Chevrolet Silverado & BMW X3 & Audi Q5 & Nissan Rogue \\
\hline 'fine san' (47) & 'excellent ultra' (29) & 'exterior interior' (357) & 'loud social' (137) \\
\hline 'hot hot' (22) & 'spacious interior' (23) & 'hybrid manual' (27) & 'social loud' (100) \\
\hline 'exterior interior' (20) & ‘automatic salaam’ (23) & 'manual manual' (24) & 'entire future' (39) \\
\hline 'interior automatic' (15) & 'read travel' (20) & 'thought possible' (24) & 'live loud' (28) \\
\hline 'good automatic' (14) & 'adventurous follow' (20) & 'possible stylish' (24) & 'gun metallic' (26) \\
\hline 'automatic pay' (14) & 'follow quote' (20) & 'stylish follow' (24) & 'fair drive' (22) \\
\hline 'ram pickup’ (12) & 'nice luxurious' (19) & 'follow quote' (24) & 'sweet electric' (13) \\
\hline 'mobile rural' (12) & 'accident original' (18) & 'automatic liberty' (21) & 'exterior interior' (12) \\
\hline 'unwrap great' (10) & 'original wide', (18) & 'digital electric' (15) & ‘sneak peek’ (9) \\
\hline 'great great' $(10)$ & 'electric electric' (17) & 'green metallic' (15) & 'great great' (8) \\
\hline 'great welcome' (9) & 'athletic refined' (17) & 'private green' (14) & 'select super' (8) \\
\hline 'key necessary’ (9) & 'refined exceptional' (17) & 'metallic nougat'(14) & 'alert tag' (8) \\
\hline 'th fantasy' (9) & 'exceptional utter' (17) & 'premium license' (14) & 'happy happy’ (7) \\
\hline 'th annual' (8) & 'luxurious beautiful' (17) & 'hybrid comfortable' (14) & 'commercial commercial' (6) \\
\hline ‘tundra pro' (8) & 'deep metallic' (16) & 'comfortable quiet' (14) & 'comfortable compact' (6) \\
\hline 'sierra interior' (8) & 'ultra bright', (15) & 'exterior metallic' (13) & 'maximum cargo' (6) \\
\hline 'good bad' (7) & 'limited reflective' (14) & 'hybrid electric'(13) & 'little good' (6) \\
\hline 'little great' (7) & 'hybrid electric' (14) & 'automatic acoustic' (13) & 'spacious interior' (5) \\
\hline 'handle handle' (7) & 'awesome nice'(14) & 'acoustic dab' (13) & 'sick little’ (5) \\
\hline 'jeep grand' (6) & 'diesel digital' (12) & 'dab digital' (13) & 'good strong' (4) \\
\hline
\end{tabular}

Notes: Frequency in brackets (descending order) 
Table 11. Most popular ICE trigrams from Twitter sample by model

\begin{tabular}{|c|c|c|c|}
\hline Chevrolet Silverado & BMW X3 & Audi Q5 & Nissan Rogue \\
\hline 'good automatic pay' (14) & $\begin{array}{c}\text { 'adventurous follow quote' } \\
(20)\end{array}$ & $\begin{array}{c}\text { 'thought possible stylish' } \\
(24)\end{array}$ & 'sick little good' (5) \\
\hline $\begin{array}{l}\text { 'exterior interior automatic' } \\
(10)\end{array}$ & $\begin{array}{l}\text { 'accident original wide' } \\
\text { (18) }\end{array}$ & $\begin{array}{l}\text { 'possible stylish follow' } \\
\text { (24) }\end{array}$ & 'door little possible’ (4) \\
\hline 'exterior tan automatic' (6) & $\begin{array}{l}\text { 'athletic refined } \\
\text { exceptional' (17) }\end{array}$ & $\begin{array}{l}\text { 'private green metallic' } \\
\text { (14) }\end{array}$ & ‘excited sure know’ (4) \\
\hline $\begin{array}{c}\text { 'interior neutral automatic' } \\
\text { (6) }\end{array}$ & $\begin{array}{l}\text { 'refined exceptional utter' } \\
\text { (17) }\end{array}$ & $\begin{array}{l}\text { 'green metallic nougat' } \\
(14)\end{array}$ & 'sure know test' (4) \\
\hline ‘key necessary green’ (5) & $\begin{array}{l}\text { 'nice luxurious beautiful' } \\
\text { (17) }\end{array}$ & 'hybrid comfortable quiet' & $\begin{array}{c}\text { 'exterior interior adventurous' } \\
\text { (3) }\end{array}$ \\
\hline 'multiple fit fantastic' (4) & $\begin{array}{l}\text { 'excellent ultra bright' } \\
\text { (14) }\end{array}$ & $\begin{array}{l}\text { 'automatic acoustic dab' } \\
\text { (13) }\end{array}$ & 'compact small ideal' (3) \\
\hline 'good unstoppable tight' (4) & $\begin{array}{c}\text { 'awesome nice luxurious' } \\
\text { (14) }\end{array}$ & 'acoustic dab digital' (13) & ‘small ideal busy' (3) \\
\hline 'unstoppable tight te' (4) & $\begin{array}{l}\text { 'spacious likely happy’ } \\
\text { (12) }\end{array}$ & 'dab digital electric' (13) & 'ideal busy tight' (3) \\
\hline $\begin{array}{c}\text { 'metallic interior automatic' } \\
\text { (4) }\end{array}$ & $\begin{array}{l}\text { 'upkeep average compact' } \\
(10)\end{array}$ & 'manual manual manual' & 'busy tight different' (3) \\
\hline 'sierra rear sierra' (4) & ‘excellent ultra angel’ (7) & $\begin{array}{l}\text { 'nice luxurious beautiful' } \\
\text { (12) }\end{array}$ & 'good strong attractive' (3) \\
\hline 'rear sierra handle' (4) & $\begin{array}{c}\text { 'android screen android' } \\
\text { (7) }\end{array}$ & $\begin{array}{l}\text { 'expect unrivaled } \\
\text { unparalleled' (11) }\end{array}$ & 'sport thought automotive' (3) \\
\hline $\begin{array}{l}\text { 'manual suburban specific' } \\
\text { (4) }\end{array}$ & $\begin{array}{l}\text { 'screen android } \\
\text { applicable' (7) }\end{array}$ & $\begin{array}{l}\text { 'fifth automatic liberty' } \\
\qquad(10)\end{array}$ & 'advanced smart choose' (3) \\
\hline $\begin{array}{l}\text { 'exterior interior neutral' } \\
\text { (4) }\end{array}$ & $\begin{array}{l}\text { 'android applicable } \\
\text { compatible' (7) }\end{array}$ & $\begin{array}{c}\text { ‘awesome nice luxurious' } \\
\text { (9) }\end{array}$ & 'smart choose compact' (3) \\
\hline 'expert pete welcome' (3) & 'plus remote virtual' (7) & 'win live premium' (8) & 'primary my drive' (3) \\
\hline 'hot short rare' (3) & 'animal sweet ride' (6) & $\begin{array}{l}\text { 'hybrid manual hybrid' } \\
\text { (8) }\end{array}$ & 'my drive present' (2) \\
\hline 'hot green short' (3) & 'excellent ultra halo' (6) & $\begin{array}{c}\text { 'manual hybrid manual' } \\
\text { (8) }\end{array}$ & 'drive present intact' (2) \\
\hline ‘slide key necessary’ (3) & ‘macan macan macan’ (6) & $\begin{array}{c}\text { 'arrive extra exterior' } \\
\text { (7) }\end{array}$ & 'present intact intact' (2) \\
\hline 'hot hot collectible' (3) & $\begin{array}{l}\text { 'crystal panoramic } \\
\text { automatic' (6) }\end{array}$ & $\begin{array}{c}\text { 'exterior metallic beige' } \\
(6)\end{array}$ & $\begin{array}{l}\text { 'commercial commercial } \\
\text { commercial' (2) }\end{array}$ \\
\hline $\begin{array}{l}\text { 'awesome affordable } \\
\text { repairable' (3) }\end{array}$ & $\begin{array}{c}\text { 'panoramic automatic } \\
\text { great' }(6)\end{array}$ & 'fit blank ceramic' (6) & 'consecutive award compact' (2) \\
\hline $\begin{array}{l}\text { 'exterior metallic interior' } \\
\text { (3) }\end{array}$ & 'ultra bright halo’ (5) & $\begin{array}{l}\text { 'double panoramic } \\
\text { automatic' (6) }\end{array}$ & 'happy automotive fresh' (2) \\
\hline
\end{tabular}

Notes: Frequency in brackets (descending order) 


\section{Appendix A \\ Raw Python Code}

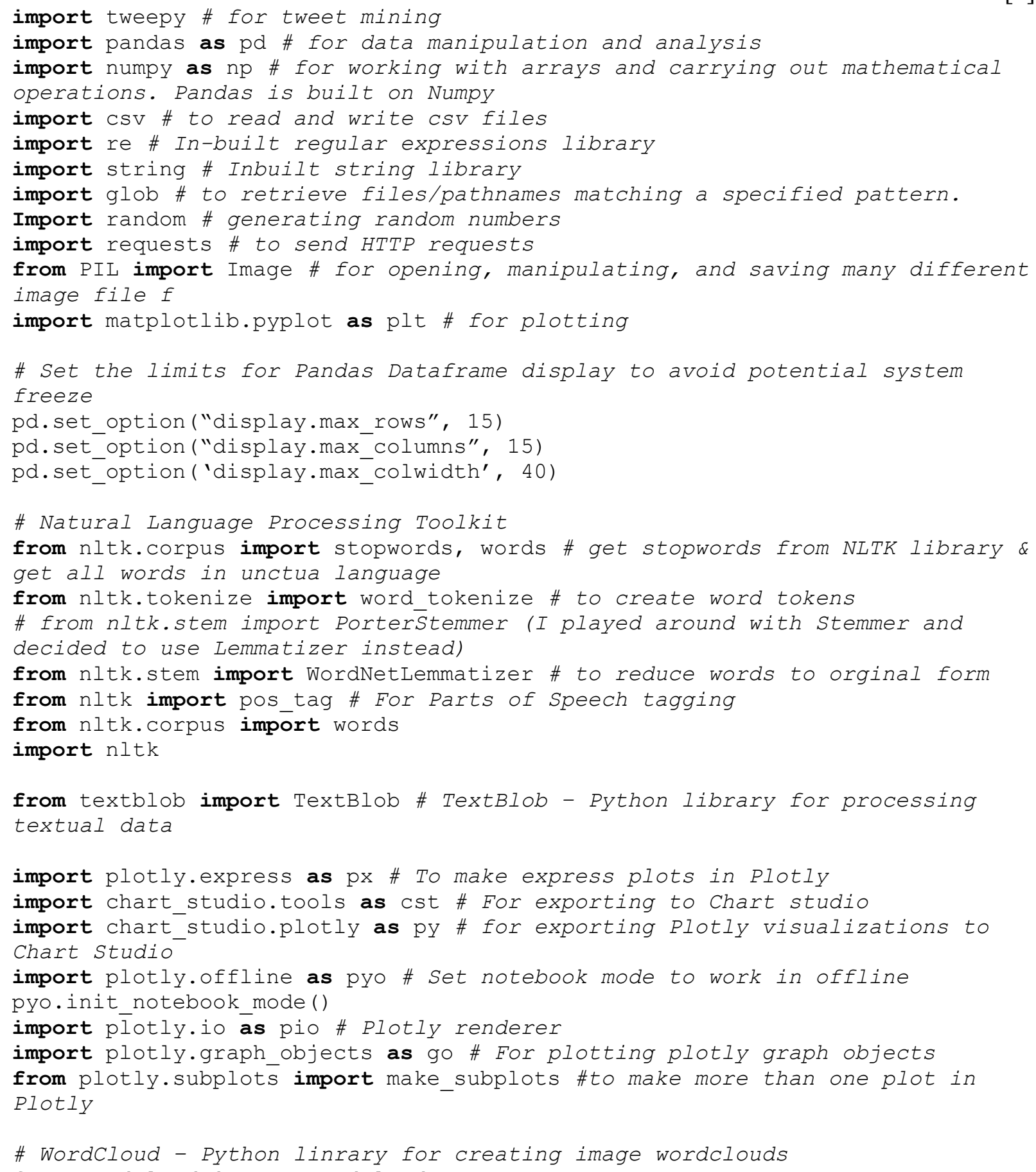




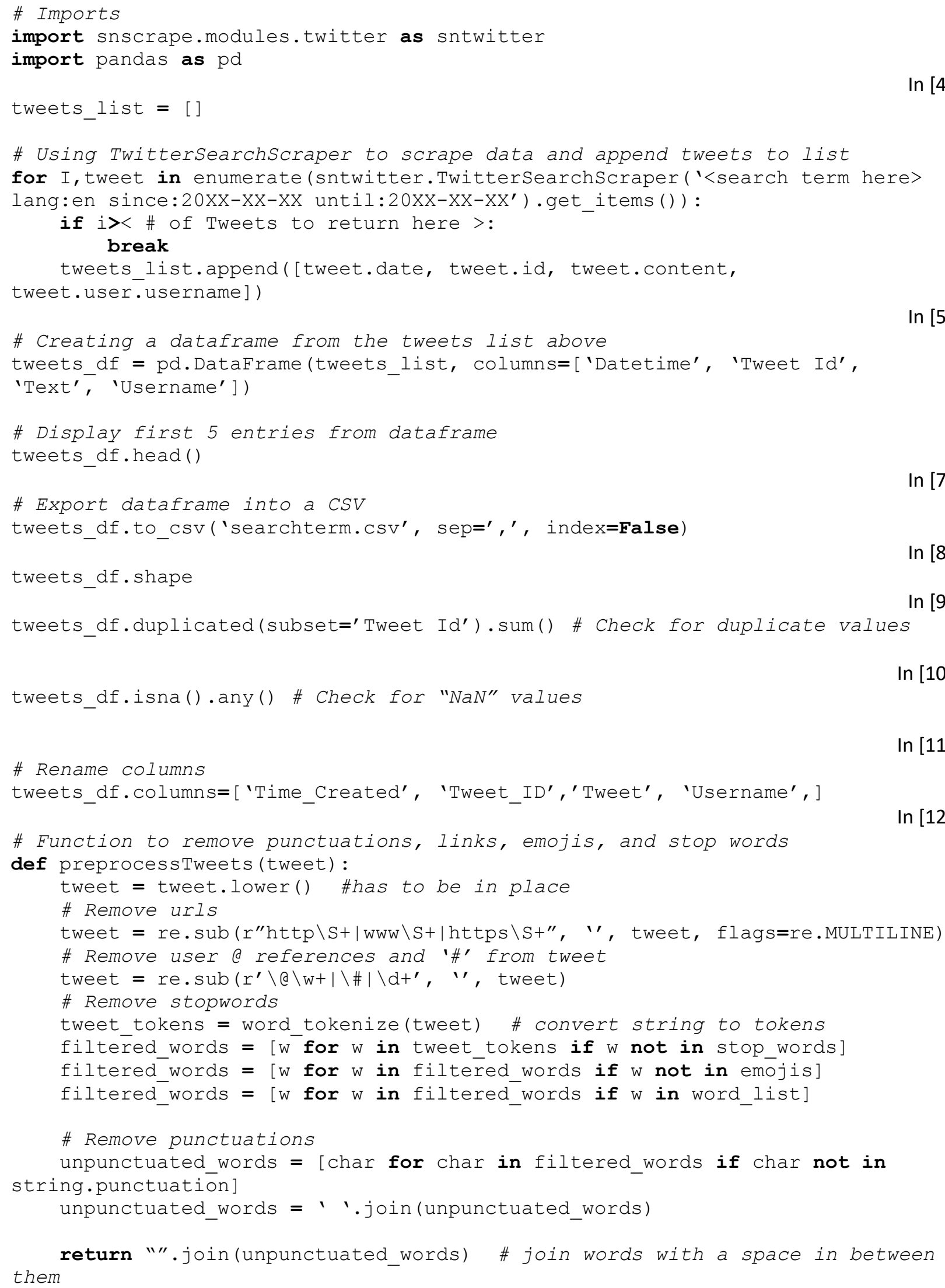




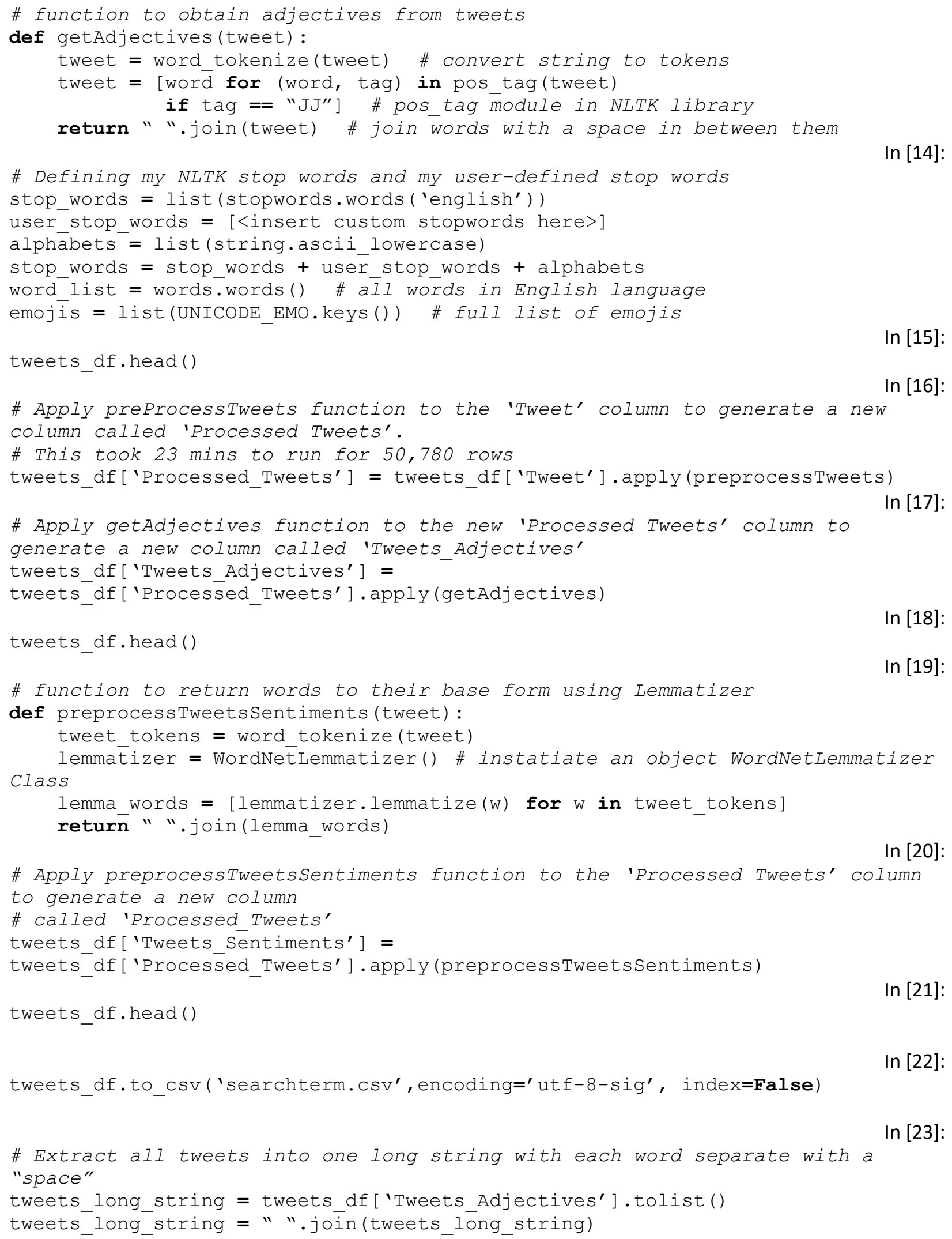




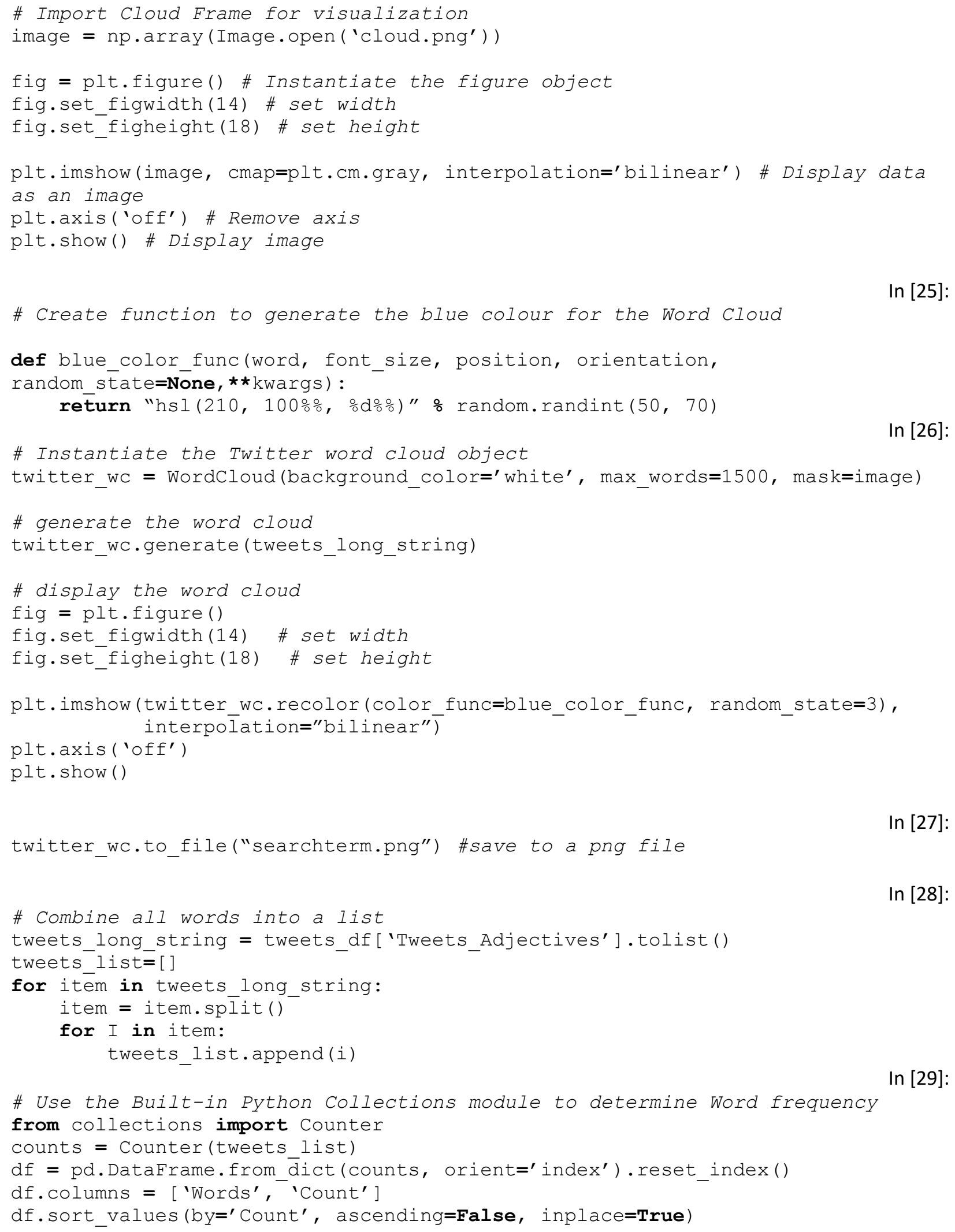


\# Define my colours for the Plotly Plot

$\ln [31]:$

$\operatorname{colors}=\left[\operatorname{rgb}(8,48,107)^{\prime}, \operatorname{\prime rgb}(8,81,156)^{\prime}, \operatorname{'rgb}(33,113,181)^{\prime}\right.$,

'rgb $(66,146,198)$ ',

'rgb $(107,174,214)$ ', 'rgb $(158,202,225)$ ' ' 'rgb $(198,219,239)$ ',

'rgb $(222,235,247)^{\prime}, \operatorname{rgb}(247,251,255)$ ' ' 'rgb $(247,253,255)$ ' ]

\# Set layout for Plotly Subplots

fig = make_subplots $($ rows $=1, \operatorname{cols}=2, \operatorname{specs}=[[\{$ "type": "xy" $\},\{$ "type":

"domain"\}] ],

vertical_spacing=0.001)

\# Add First Plot

fig.add trace (go.Bar $(\mathrm{x}=\mathrm{df}[$ 'Count'].head(10),

$\mathrm{y}=\mathrm{df}[$ 'Words' $]$. head (10), marker=dict $(\operatorname{color}=' \operatorname{rgba}(66,146,198,1) '$,

line=dict $($ color='Black'), ), name='Bar Chart', orientation='h' ), 1 ,

1)

\# Add Second Plot

fig.add trace (go.Pie (labels=df ['Words'] .head (10), values=df [ 'Count'] .head (15) , textinfō'label+percent', insidetextorientation=' radial',

marker=dict (colors=colors, line=dict (color=' DarkslateGrey') ), name ${ }^{\prime}$ Pie Chart'), 1, 2)

\# customize layout

fig.update_layout (shapes=[dict (type="line", xref="paper", yref="paper",

$\mathrm{x} 0=0.5, \mathrm{y} 0=0, \mathrm{x} 1=0.5, \mathrm{y} 1=1.0$,

line_color='DarkSlateGrey', line_width=1)] )

\# customize plot title

fig.update layout (showlegend=False, title=dict(text="BMW i3 2020 Tweet

Summary $\langle i \overline{>}(10$ Most Common Words $)</ i>$ ", font=dict $(\operatorname{size}=18))$,

\# Customize unctuatio, margins, axis, title

fig.update_layout (yaxis=dict (showgrid=False, showline=False, showticklabels=True, domain= $[0,1]$, categoryorder $\boldsymbol{~}^{\prime}$ total ascending', title=dict $\left(\right.$ text $=^{\prime}$ Common Words', font_size=14)), xaxis=dict $($ zeroline=False, showline=False, showticklabels=True, showgrid=True, domain=[0,0.42], title=dict (text='Word Count', font_size=14)), margin=dict $(l=100, r=20, t=70, b=7 \overline{0})$, paper_bgcolor $=^{\prime} \operatorname{rgba}(0,0,0,0)^{\prime}$, plot_bgcolor $\left.{ }^{\prime} \operatorname{rgba}(0,0,0,0)^{\prime}\right)$

\# Specify $X$ and $Y$ values for Annotations

$\mathrm{x}=\mathrm{df}[$ 'Count'].head(10).to list()

$y=d f[$ 'Words'] .head (10).to_list()

\# Show annotations on plot 


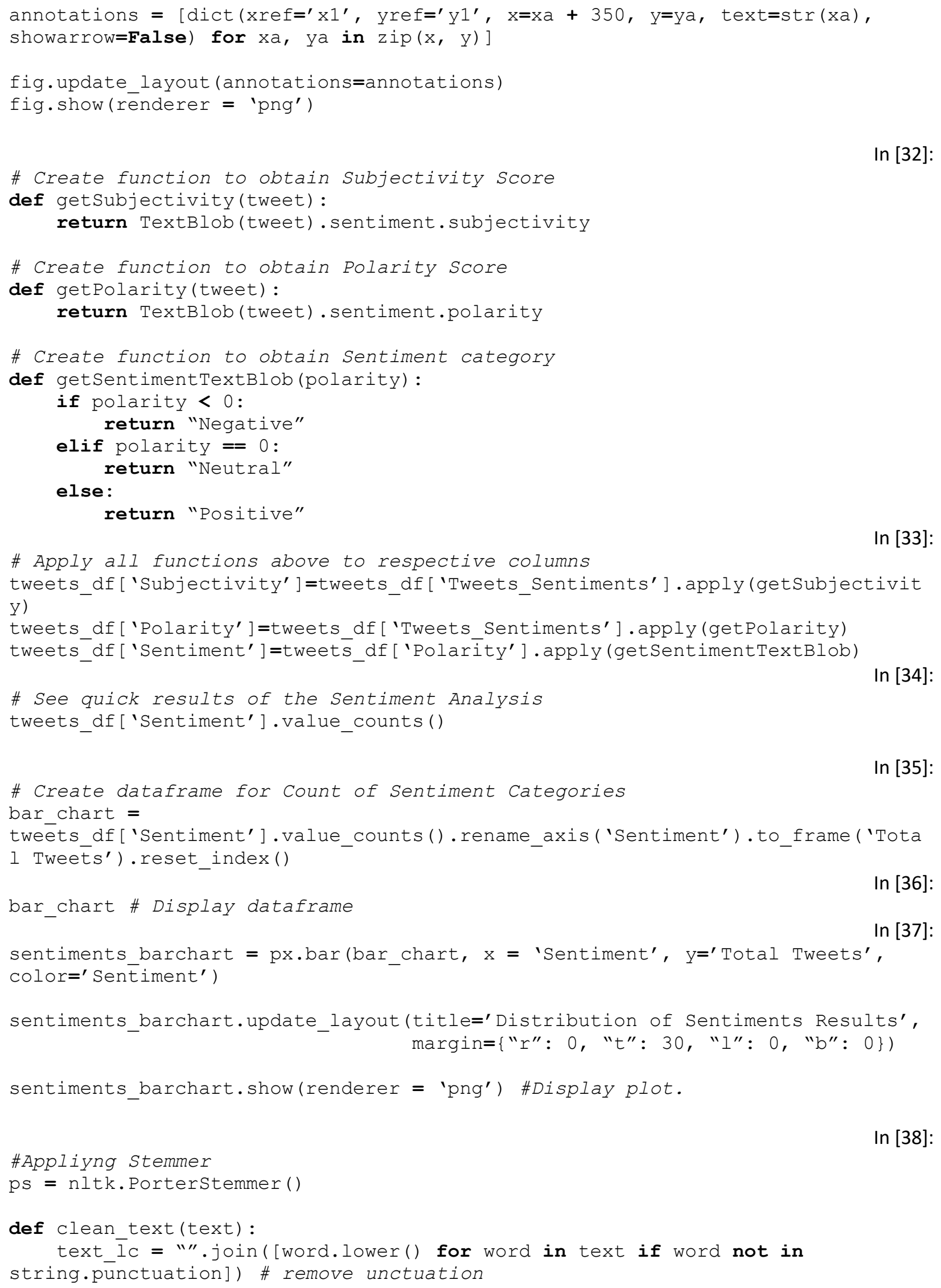




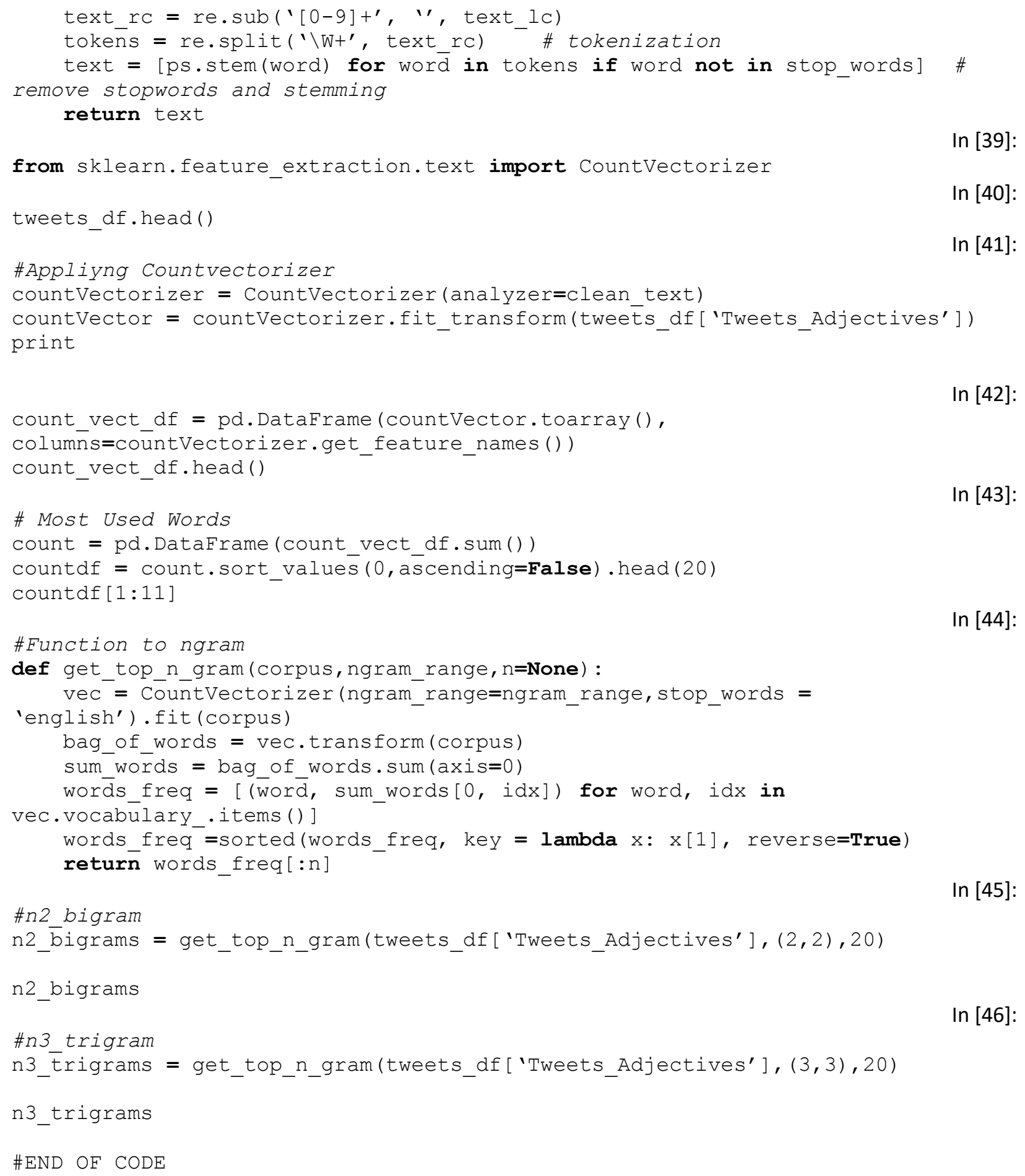




\title{
Appendix B
}

\section{Chevrolet Bolt Manufacturer Factor Analysis}

\author{
Driving Experience \\ $\mathrm{x}$ Performance $=1$ \\ Exp. Positioning/ Lifestyle Int. \\ $\mathrm{x}$ Performance $=2$ \\ x Style Aesthetics $=1$ \\ $\mathrm{x}$ Comfort/ Convenience $=1$ \\ Design/ Manufacturing \\ $\mathrm{x}$ Comfort $/$ Convenience $=1$
}

\section{Bolt Adjectives}

\begin{tabular}{|c|c|}
\hline Important & 31 \\
\hline Compatible & 27 \\
\hline Range & 25 \\
\hline Functionality & 20 \\
\hline Connectivity & 7 \\
\hline Current & 7 \\
\hline Performance & 7 \\
\hline Limited & 6 \\
\hline Simple & 4 \\
\hline Connected & 3 \\
\hline Convenience & 3 \\
\hline Fast & 3 \\
\hline Love & 3 \\
\hline Quality & 3 \\
\hline Quick & 3 \\
\hline Special & 3 \\
\hline Audible & 2 \\
\hline Certified & 2 \\
\hline Dynamic & 2 \\
\hline Gentle & 2 \\
\hline Greater & 2 \\
\hline Old & 2 \\
\hline Potential & 2 \\
\hline Premier & 2 \\
\hline Professional & 2 \\
\hline Redesigned & 2 \\
\hline Roomy & 2 \\
\hline Sonic & 2 \\
\hline Spacious & 2 \\
\hline Surprisingly & 2 \\
\hline Accredited & 1 \\
\hline Affordable & 1 \\
\hline Approved & 1 \\
\hline Beautifully & 1 \\
\hline Bold & 1 \\
\hline Classic & 1 \\
\hline Content & 1 \\
\hline Costly & 1 \\
\hline Enhanced & 1 \\
\hline Fastest & 1 \\
\hline Foreign & 1 \\
\hline Growing & 1 \\
\hline Impressive & 1 \\
\hline Intuitively & 1 \\
\hline Longest & 1 \\
\hline
\end{tabular}




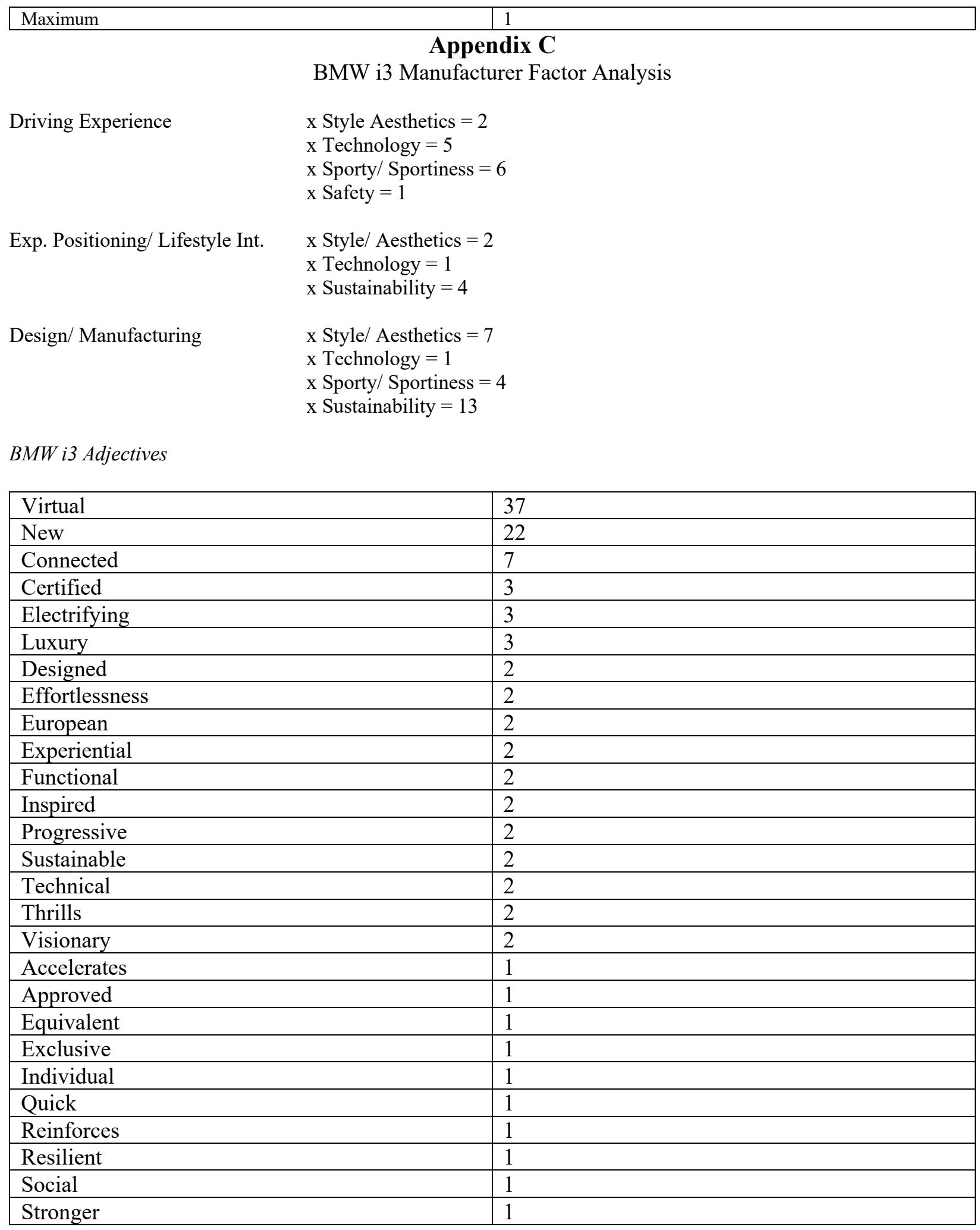




\section{Appendix D \\ Audi e-tron Manufacturer Factor Analysis}

\begin{tabular}{|c|c|}
\hline Driving Experience & $\mathrm{x}$ Technology $=4$ \\
\hline Exp. Positioning/ Lifestyle Int. & $\begin{array}{l}\text { x Performance }=2 \\
\text { x Technology }=7 \\
\text { x Style/ Aesthetics }=4 \\
\text { x Comfort } / \text { Convenience }=1\end{array}$ \\
\hline Technology & $\begin{array}{l}x \text { Safety }=2 \\
x \text { Comfort } / \text { Convenience }=5\end{array}$ \\
\hline Design/ Manufacturing & $\begin{array}{l}\text { x Technology }=6 \\
\text { x Style/ Aesthetics }=9 \\
\text { x Comfort/ Convenience }=1\end{array}$ \\
\hline
\end{tabular}

Audi Heritage

$\mathrm{x}$ Technology $=5$

\section{Audi eTron Adjectives}

\begin{tabular}{|l|l|}
\hline European & 5 \\
\hline New & 5 \\
\hline Range & 3 \\
\hline Beauty & 2 \\
\hline Certified & 2 \\
\hline Current & 2 \\
\hline Performance & 2 \\
\hline Special & 2 \\
\hline Unique & 2 \\
\hline Virtual & 2 \\
\hline Activated & 1 \\
\hline Aerodynamic & 1 \\
\hline Approved & 1 \\
\hline Beautiful & 1 \\
\hline Boutique & 1 \\
\hline Crafted & 1 \\
\hline Created & 1 \\
\hline Endless & 1 \\
\hline Environmental & 1 \\
\hline Equivalent & 1 \\
\hline Exclusive & 1 \\
\hline Futuristic & 1 \\
\hline Informed & 1 \\
\hline Innovative & 1 \\
\hline Refined & 1 \\
\hline Reserved & 1 \\
\hline Sculpted & 1 \\
\hline Technical & 1 \\
\hline
\end{tabular}




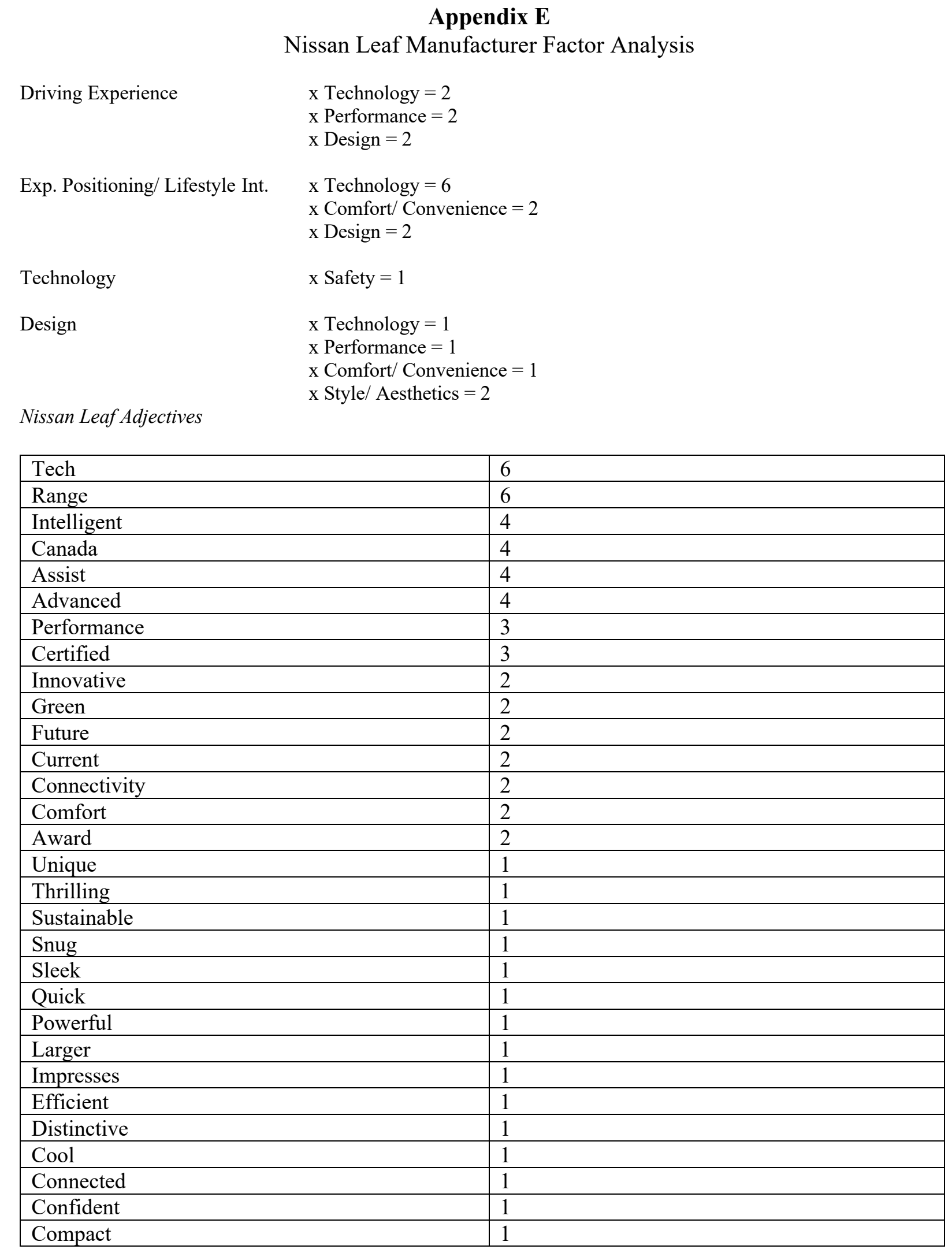




\section{Appendix F}

\section{Chevrolet Silverado Manufacturer Factor Analysis}

Driving Experience

Exp. Positioning/ Lifestyle Int.

Design/ Manufacturing

Fuel Efficiency $\mathrm{x}$ Technology $=1$

$\mathrm{x}$ Style/ Aesthetics $=1$

$\mathrm{x}$ Performance $=5$

$\mathrm{x}$ Technology $=3$

$\mathrm{x}$ Comfort $/$ Convenience $=2$

$\mathrm{x}$ Performance $=6$

$\mathrm{x}$ Technology $=3$

$\mathrm{x}$ Comfort $/$ Convenience $=1$

$\mathrm{x}$ Safety $=1$

$\mathrm{x}$ Performance $=2$

\section{Silverado Adjectives}

\begin{tabular}{|c|c|}
\hline Important & 34 \\
\hline Country & 33 \\
\hline Custom & 31 \\
\hline Compatible & 30 \\
\hline Standard & 23 \\
\hline Active & 16 \\
\hline Features & 14 \\
\hline Advanced & 7 \\
\hline Appropriate & 7 \\
\hline Connected & 4 \\
\hline Independent & 4 \\
\hline Strong & 4 \\
\hline United & 4 \\
\hline Impressive & 2 \\
\hline Informative & 2 \\
\hline Polished & 2 \\
\hline Premium & 2 \\
\hline Rugged & 2 \\
\hline Spacious & 2 \\
\hline Traditional & 2 \\
\hline Wrangler & 2 \\
\hline Commanding & 1 \\
\hline Customized & 1 \\
\hline Deluxe & 1 \\
\hline Durable & 1 \\
\hline Exclusive & 1 \\
\hline Fastest & 1 \\
\hline Formed & 1 \\
\hline Hardworking & 1 \\
\hline Hooked & 1 \\
\hline Ingenious & 1 \\
\hline Innovative & 1 \\
\hline Inspired & 1 \\
\hline Legendary & 1 \\
\hline Old & 1 \\
\hline Powerful & 1 \\
\hline Premium & 1 \\
\hline Strongest & 1 \\
\hline Suburban & 1 \\
\hline
\end{tabular}




\begin{tabular}{|l|l|}
\hline Tough & 1 \\
\hline Versatile & 1 \\
\hline
\end{tabular}

\section{Appendix G}

\section{BMW X3 Manufacturer Factor Analysis}

Driving Experience

$\mathrm{x}$ Style $/$ Aesthetics $=1$

$\mathrm{x}$ Experiential Positioning $=1$

$\mathrm{x}$ Technology $=7$

$\mathrm{x}$ Performance $=4$

Exp. Position/ Lifestyle Int.

x Aesthetics/ Style $=7$

$\mathrm{x}$ Technology $=3$

$\mathrm{x}$ Sporty $/$ Sportiness $=4$

Safety

$\mathrm{x}$ Technology $=2$

Design/ Manufacturing

$\mathrm{x}$ Style/ Aesthetics $=1$

$\mathrm{x}$ Experiential Positioning/ Lifestyle Integration $=1$

BMW X3 Adjectives

\begin{tabular}{|l|l|}
\hline Virtual & 40 \\
\hline New & 16 \\
\hline Connected & 7 \\
\hline Special & 7 \\
\hline Certified & 3 \\
\hline Luxury & 3 \\
\hline Competition & 2 \\
\hline European & 2 \\
\hline Experiential & 2 \\
\hline Performance & 2 \\
\hline Sport & 2 \\
\hline Activated & 1 \\
\hline Approved & 1 \\
\hline Athletic & 1 \\
\hline Autonomous & 1 \\
\hline Comfort & 1 \\
\hline Compatible & 1 \\
\hline Concept & 1 \\
\hline Exciting & 1 \\
\hline Exclusive & 1 \\
\hline Great & 1 \\
\hline Impress & 1 \\
\hline Intelligent & 1 \\
\hline Redefines & 1 \\
\hline Social & 1 \\
\hline Supreme & 1 \\
\hline Tempered & 1 \\
\hline
\end{tabular}




\section{Appendix H}

\section{Audi Q5 Manufacturer Factor Analysis}

\begin{tabular}{|c|c|}
\hline Driving Experience & $\begin{array}{l}x \text { Performance }=1 \\
x \text { Technology }=4\end{array}$ \\
\hline Exp. Positioning/ Lifestyle Int. & $\begin{array}{l}\text { x Performance }=1 \\
\text { x Comfort } / \text { Convenience }=2 \\
\text { x Style } / \text { Aesthetics }=3\end{array}$ \\
\hline Technology & $\begin{array}{l}\mathrm{x} \text { Comfort } / \text { Convenience }=1 \\
\mathrm{x} \text { Safety }=2\end{array}$ \\
\hline Design/ Manufacturing & $\begin{array}{l}\text { x Performance }=1 \\
\mathrm{x} \text { Comfort } / \text { Convenience }=1 \\
\mathrm{x} \text { Style } / \text { Aesthetics }=3\end{array}$ \\
\hline Audi Heritage & $\begin{array}{l}\mathrm{x} \text { Performance }=1 \\
\mathrm{x} \text { Style/ Aesthetics }=3\end{array}$ \\
\hline
\end{tabular}

\section{Audi Q5 Adjectives}

\begin{tabular}{|l|l|}
\hline New & 6 \\
\hline Certified & 2 \\
\hline Current & 2 \\
\hline Special & 2 \\
\hline Standard & 2 \\
\hline Unique & 2 \\
\hline Activated & 1 \\
\hline Benchmark & 1 \\
\hline Boutique & 1 \\
\hline Canadian & 1 \\
\hline Characteristic & 1 \\
\hline Complete & 1 \\
\hline Defined & 1 \\
\hline Exceptional & 1 \\
\hline Exclusive & 1 \\
\hline Expressive & 1 \\
\hline Imagined & 1 \\
\hline Informed & 1 \\
\hline Luxury & 1 \\
\hline Mild & 1 \\
\hline Oasis & 1 \\
\hline Outstanding & 1 \\
\hline Pioneering & 1 \\
\hline Powerful & 1 \\
\hline Quality & 1 \\
\hline Sculpted & 1 \\
\hline Sport & 1 \\
\hline Style & 1 \\
\hline Technical & 1 \\
\hline Ultimate & 1 \\
\hline
\end{tabular}




\section{Appendix I}

\section{Nissan Rogue Manufacturer Factor Analysis}

Driving Experience

$\mathrm{x}$ Performance $=3$

$\mathrm{x}$ Technology $=5$

Exp. Positioning/ Lifestyle Int. $x$ Performance $=2$

$\mathrm{x}$ Style/ Aesthetics $=2$

$\mathrm{x}$ Family $=2$

$\mathrm{x}$ Technology $=2$

$\mathrm{x}$ Comfort/ Convenience $=2$

Technology

$\mathrm{x}$ Safety $=10$

$\mathrm{x}$ Comfort/ Convenience $=2$

Design

$\mathrm{x}$ Technology $=1$

$\mathrm{x}$ Comfort $/$ Convenience $=3$

Nissan Rogue Adjectives

\begin{tabular}{|l|l|}
\hline New & 14 \\
\hline Intelligent & 6 \\
\hline Standard & 5 \\
\hline Best & 4 \\
\hline Crossover & 4 \\
\hline Certified & 3 \\
\hline Comfort & 3 \\
\hline Competition & 3 \\
\hline Current & 2 \\
\hline Designed & 2 \\
\hline Friendly & 2 \\
\hline Performance & 2 \\
\hline Protection & 2 \\
\hline Ready & 2 \\
\hline Virtual & 2 \\
\hline Welcome & 2 \\
\hline Advanced & 1 \\
\hline Awarded & 1 \\
\hline Conquer & 1 \\
\hline Enhancing & 1 \\
\hline Exciting & 1 \\
\hline Extraordinary & 1 \\
\hline Familiar & 1 \\
\hline Imagined & 1 \\
\hline Impressive & 1 \\
\hline Premium & 1 \\
\hline Quilted & 1 \\
\hline & \\
\hline
\end{tabular}




\begin{tabular}{|l|l|}
\hline Unique & 1 \\
\hline Versatile & 1 \\
\hline Wider & 1 \\
\hline
\end{tabular}

Appendix J

\section{Most Tweeted Words}

a)

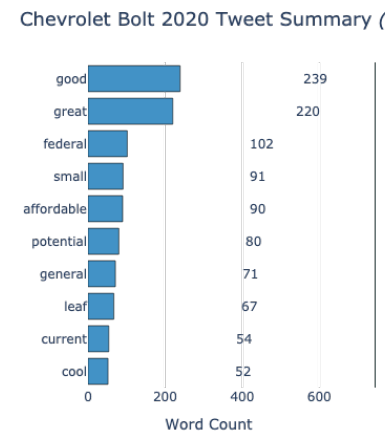

c)

Audi eTron 2020 Tweet Summary (10 Most Common Words)

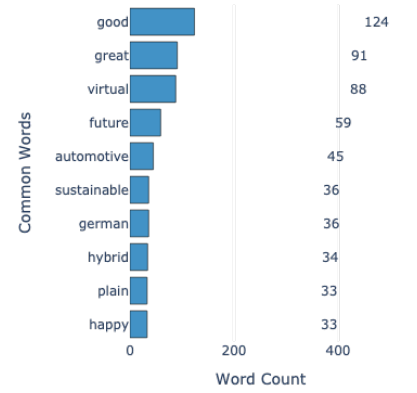

e)

Chevy Silverado 2020 Tweet Summary (10 Most Common Words)

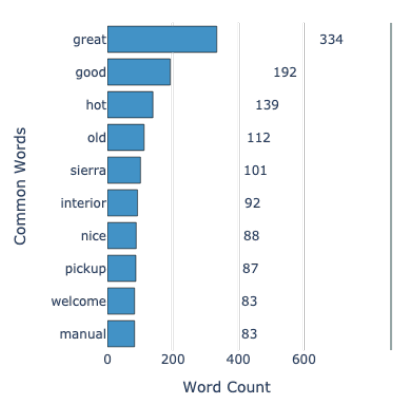

g) b)

BMW i3 2020 Tweet Summary (10 Most Common Words)

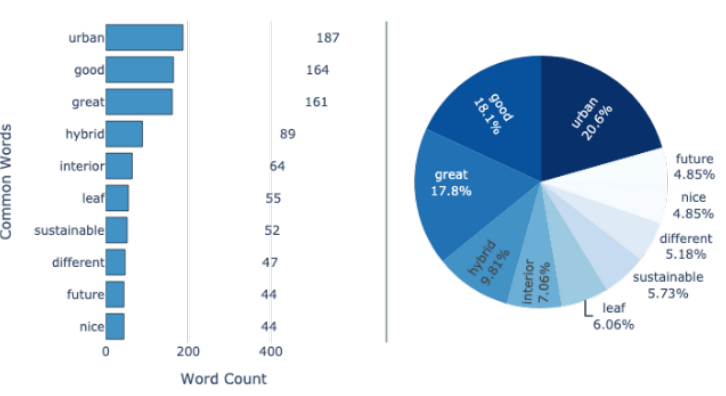

d)

Nissan Leaf 2020 Tweet Summary (10 Most Common Words)
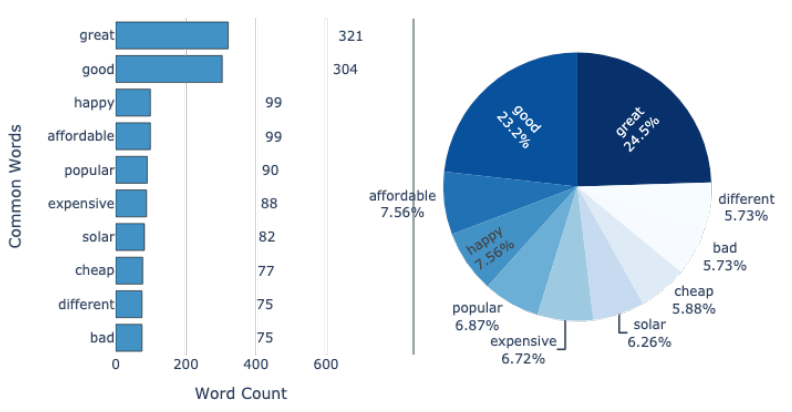

f)

BMW X3 2020 Tweet Summary (10 Most Common Words)
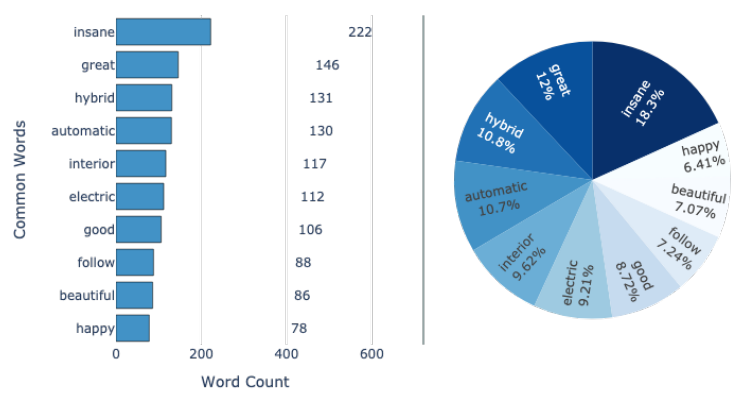

h) 
Audi Q5 2020 Tweet Summary (10 Most Common Words)

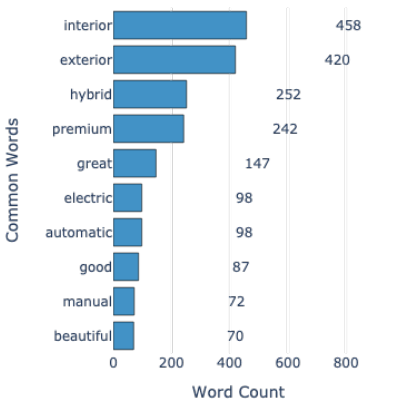

Nissan Rogue 2020 Tweet Summary (10 Most Common Words)

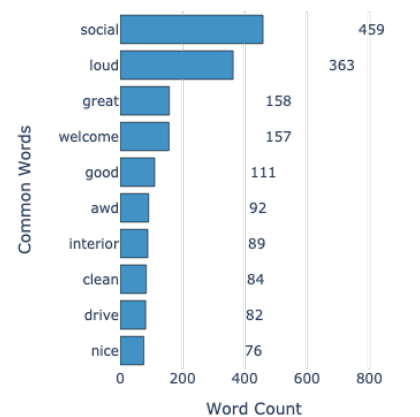

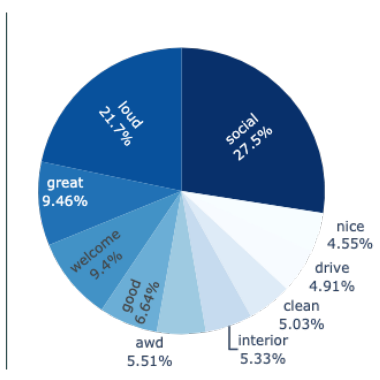




\section{Bibliography}

Allison, W. (2003, December 1). 2004 Car of the Year Winner - 2004 Toyota Prius - Motor Trend. MotorTrend. https:/www.motortrend.com/cars/toyota/prius/2004/04-coy-win/.

Audi. (2021a). Audi. 2021 Audi e-tron. https://www.audi.ca/ca/web/en/models/etron/e-tronquattro.html.

Audi. (2021b). Audi. 2021 Audi Q5. https://www.audi.ca/ca/web/en/models/q5/q5.html.

Balwant, P. T. (2020). Crisis leadership: Teaching external corporate communications via an experiential learning exercise. Journal of Education for Business, 1-8. https://doi.org/10.1080/08832323.2020.1829526

Bannon, E. (2021, April 12). In cities 63\% support EU ban on petrol and diesel car sales after 2030. Transport \& Environment. https://www.transportenvironment.org/press/cities-63support-eu-ban-petrol-and-diesel-car-sales-after-2030.

Bauer, G., Hsu, C.-W., \& Lutsey, N. (2021). When might lower-income drivers benefit from electric vehicles? Quantifying the economic equity implications of electric vehicle adoption. International Council on Clean Transportation, 1-18.

Baum, D., Spann, M., Füller, J., \& Thürridl, C. (2019). The impact of social media campaigns on the success of new product introductions. Journal of Retailing and Consumer Services, 50, 289-297. https://doi.org/10.1016/j.jretconser.2018.07.003 
Beck, M. (2020, January 12). How to Scrape Tweets From Twitter. Towards Data Science. https://towardsdatascience.com/how-to-scrape-tweets-from-twitter-59287e20f0f1.

Bellan, R. (2018, October 15). The Grim State of Electric Vehicle Adoption in the U.S. Bloomberg.com. https://www.bloomberg.com/news/articles/2018-10-15/the-state-ofelectric-vehicle-adoption-in-the-u-s.

Bennett, R., Kottasz, R., \& Shaw, S. (2016). Factors potentially affecting the successful promotion of electric vehicles. Journal of Social Marketing, 6(1), 62-82. doi:10.1108/jsocm-08-2015-0059

Biden, J. (2021, May 18). Remarks by President Biden on a Future Made in America. The White House. https://www.whitehouse.gov/briefing-room/speeches-remarks/2021/05/18/remarksby-president-biden-on-a-future-made-in-america/.

BMW. (2021a). BMW. BMW i3. https://www.bmw.ca/en/all-models/bmw-i/i3/2017/at-aglance.html.

BMW. (2021b). BMW. BMW X3. https://www.bmw.ca/en/all-models/x-series/X3/2017/at-aglance.html.

Boffey, D. (2019, May 3). Amsterdam to ban petrol and diesel cars and motorbikes by 2030. The Guardian. https://www.theguardian.com/world/2019/may/03/amsterdam-ban-petrol-dieselcars-bikes-2030. 
Brady, J., \& O'Mahony, M. (2011). Introduction of Electric Vehicles to Ireland. Transportation Research Record: Journal of the Transportation Research Board, 2242(1), 64-71. https://doi.org/10.3141/2242-08

Butters, J. (2017, November 30). Take Your Pick From 150 Models in America's Saturated SUV Market. Industry Week. https://www.industryweek.com/innovation/productdevelopment/article/22024649/take-your-pick-from-150-models-in-americas-saturatedsuv-market.

California, S. of. (2021, April 26). Governor Newsom Announces California Will Phase Out Gasoline-Powered Cars \& Drastically Reduce Demand for Fossil Fuel in California's Fight Against Climate Change. California Governor. https://www.gov.ca.gov/2020/09/23/governor-newsom-announces-california-will-phaseout-gasoline-powered-cars-drastically-reduce-demand-for-fossil-fuel-in-californias-fightagainst-climatechange/\#: :text=SACRAMENTO $\% 20 \%$ E2\%80\%93\%20Governor\%20Gavin $\% 20$ Newsom \%20today,passenger\%20vehicles $\% 20$ to $\% 20$ be $\% 20$ zero $\% 2 \mathrm{D}$.

Canada, N. R. (2021, June 16). Government of Canada. Natural Resources Canada. https://www.nrcan.gc.ca/energy-efficiency/transportation-alternative-fuels/zero-emissionvehicle-infrastructure-program/21876.

Chen, S. (2016). Selling the environment: Green marketing discourse in China's automobile advertising. Discourse, Context \& Media, 12, 11-19. https://doi.org/10.1016/j.dcm.2016.03.003 
Chevrolet. (2021a). Chevrolet. 2021 Chevy Bolt | Bolt EV. https://www.chevrolet.com/electric/bolt-ev.

Chevrolet. (2021b). Chevrolet. 2021 Chevy Silverado 1500 | Pickup Truck. https://www.chevrolet.com/trucks/silverado/1500.

Cooper, L. G. (2000). Strategic marketing planning for radically new products. Journal of Marketing, 64(1), 1-16. doi:10.1509/jmkg.64.1.1.17987

Davies, R. (2020, January 2). The rise and fall of the Hummer, America's most needlessly masculine vehicle. Vox. https://www.vox.com/the-goods/2020/1/2/20992114/hummermasculinity-america-humvee-schwarzenegger.

Dehkordi, A., Yonekura, M., \& Kohnepushi, S. (2013). Descriptive analysis of NISSAN'S electric vehicle commercialization strategies. Journal of Product \& Brand Management, 22(5/6), 393-403. doi:10.1108/jpbm-04-2013-0293

Dugdale, M. (2018, August 1). European countries banning fossil fuel cars and switching to electric. Road Traffic Technology. https://www.roadtraffictechnology.com/features/european-countries-banning-fossil-fuel-cars/.

Electric Power Research Institute. (2007). Environmental Assessment of Plug-In Hybrid Electric Vehicles.

Electrify Canada: EV public charging network: Electrify Canada. Electrify America. (2021). https://www.electrify-canada.ca/. 
Environment: Science and Policy for Sustainable Development, 48(5), 22-36. https://doi.org/10.3200/envt.48.5.22-36

EV Keyword Search. Google Trends. (n.d.). https://trends.google.com/trends.

Gärling, A., \& Thogersen, J. (2001). Marketing of electric vehicles. Business Strategy and the Environment, 10(1), 53-65. doi:10.1002/1099-0836(200101/02)10:13.0.co;2-e

GMC Hummer Electric Truck: General Motors. GMC Hummer Electric Truck | General Motors. (n.d.). https://www.gm.com/masthead-story/hummer-electric-truck-ev.html.

Government of Canada (2021, June 21). Natural Resources Canada. https://www.nrcan.gc.ca/energy-efficiency/transportation-alternative-fuels/zero-emissionvehicle-infrastructure-program/21876.

Government of Ontario, M. of T. (2013, October 25). High Occupancy Vehicle (HOV) Lanes. Ministry of Transportation. http://www.mto.gov.on.ca/english/ontario-511/hovlanes.shtml\#: :text=Support\%20electric\%20vehicles\%20\%3A\%20Vehicles\%20with,one\% 20person $\% 20$ in $\% 20$ the $\% 20$ vehicle.

Graham, T. (2021). History of the Chevrolet Silverado. Car Covers. https://www.carcovers.com/resources/history-of-chevrolet.

Hardman, S., Shiu, E., \& Steinberger-Wilckens, R. (2015). Changing the fate of fuel Cell Vehicles: Can lessons be learnt from Tesla motors? International Journal of Hydrogen Energy, 40(4), 1625-1638. doi:10.1016/j.ijhydene.2014.11.149 
JustAnotherArchivist. (2018, October 9). sns scrape. GitHub. https://github.com/JustAnotherArchivist/snscrape.

Khraim, H. (2020). An exploratory study on factors associated with consumers' post-purchase dissonance of electric vehicles. Innovative Marketing, 16(4), 13-23. doi:10.21511/im.16(4).2020.02

Koptyug, E. (2021). Topic: Automobile industry in Germany. Statista. https://www.statista.com/topics/3202/automobile-industry-ingermany/\#dossierSummary_chapter1.

Krivevski, B. (2014, June 27). 2015 Nissan Leaf. Truemag. https://electriccarsreport.com/2014/06/2015-nissan-leaf/.

Lantis. (1998, January 1). Simulations and Experiential Learning in the International Relations Classroom. Brill. https://brill.com/view/journals/iner/3/1/article-p39_3.xml.

Levitt, T. (1960). Marketing Myopia. Harvard Business Review, 38, 45-56.

Luedicke, M. K. (2006). Brand Community Under Fire: The Role of Social Environments for the HUMMER Brand Community. Advances in Consumer Research, 33, 486.

Martinez, M. (2019, May 6). Ford pushes to overtake Toyota hybrid sales. Automotive News. https://www.autonews.com/marketing/ford-pushes-overtake-toyota-hybrid-sales.

McCarthy, P. S., \& Tay, R. (1989). Consumer valuation of new car attributes: An econometric analysis of the demand for domestic and Japanese/Western European imports. 
Transportation Research Part A: General, 23(5), 367-375. https://doi.org/10.1016/01912607(89)90084-8

Moons, I., \& De Pelsmacker, P. (2014). Developing different types of anticipated experience positioning for electric cars. Journal of Brand Management, 21(3), 216-235. doi:10.1057/bm.2014.2

Morgan, J. (2020). Electric vehicles: The future we made and the problem of unmaking it. Cambridge Journal of Economics, 44(4), 953-977. doi:10.1093/cje/beaa022

Nissan. (2021a). The All-New 2021 Nissan LEAF 100\% EV: Nissan Canada. Nissan. https://www.nissan.ca/vehicles/electric-cars/leaf.html.

Nissan. (2021b). Nissan. 2021 Nissan Rogue ${ }^{\circledR}$ Crossover: Nissan Canada. https://www.nissan.ca/vehicles/crossovers-suvs/rogue.html.

O'Dell, J. (2005, August 27). Prices Soar for Hybrids With Rights to Fast Lane. Los Angeles Times. https://www.latimes.com/archives/la-xpm-2005-aug-27-fi-prius27-story.html.

Ottman, J. A., Stafford, E. R., \& Hartman, C. L. (2006). Avoiding Green Marketing Myopia: Ways to Improve Consumer Appeal for Environmentally Preferable Products. Environment: Science and Policy for Sustainable Development, 48(5), 22-36. https://doi.org/10.3200/envt.48.5.22-36

Porsche. (2021). Porsche Macan. Porsche Canada. https://www.porsche.com/canada/en/models/macan/macan-models/macan/. 
Parment, A. (2015). Auto brand: Building successful car brands for the future. London: KoganPage.

Posaner, J. (2021, March 10). Death rattle of the internal combustion engine sparks a political battle. POLITICO. https://www.politico.eu/article/germany-slams-push-for-eu-car-banplan/.

Reuters. (2018, October 11). Germany backs EU climate deal over car lobby's protests. www.ETAuto.com, The Economic Times. https://auto.economictimes.indiatimes.com/news/passenger-vehicle/cars/germany-backseu-climate-deal-over-car-lobbys-protests/66158848.

Robeers, T. (2019). 'We go green in Beijing': situating live television, urban motor sport and environmental sustainability by means of a framing analysis of TV broadcasts of Formula E. Sport in Society, 22(12), 2089-2103. https://doi.org/10.1080/17430437.2018.1558212

Rosenberger, P. J., \& Donahay, B. (2008). Brand Personality Differentiation in Formula One Motor Racing: An Australian View. Marketing Bulletin, 19(2), 1-14. https://doi.org/http://marketing-bulletin.massey.ac.nz/

Ruffo, G. H. (2020, December 31). Chevy Bolt EV Has A Clunking Issue With Its Torsion Beam. InsideEVs. https://insideevs.com/news/463735/chevy-bolt-ev-clunking-issue-torsionbeam/. 
Schultz, E. J., \& Lutz, H. (2021, January 8). See how General Motors updated its logo for only the fifth time in its history. Ad Age. https://adage.com/article/cmo-strategy/see-howgeneral-motors-updated-its-logo-only-fifth-time-its-history/2304376.

Silvestro, B. (2020, July 28). The Volkswagen e-Golf Is Dead. Road \& Track. https://www.roadandtrack.com/new-cars/a31 192023/the-volkswagen-e-golf-is-dead/.

Simms, C. D., \& Trott, P. (2006). The perceptions of the BMW Mini brand: the importance of historical associations and the development of a model. Journal of Product \& Brand Management, 15(4), 228-238. https://doi.org/10.1108/10610420610679593

Sinclair, \& Rockwell, G. (2016). Version (Web). Voyant Tools. http://voyant-tools.org/.

Spurgeon, C. (2007). Advertising and new media of mass conversion. In Advertising and new media (pp. 1-23). Chapter 1, Taylor \& Francis Group.

Tesla Model 3. Tesla. (2021). https://www.tesla.com/en_ca/model3.

Topham, G., Clarke, S., Levett, C., Scruton, P., \& Fidler, M. (2015, September 23). The Volkswagen Emissions Scandal Explained. The Guardian. https://www.theguardian.com/business/ng-interactive/2015/sep/23/volkswagen-emissionsscandal-explained-diesel-cars.

Transport Canada. (2020, January 31). Zero-emission vehicles. Transport Canada. https://tc.canada.ca/en/road-transportation/innovative-technologies/zero-emission-vehicles. 
Theil, W. (2021). 2020 US Vehicle Sales Figures By Model. GCBC. https://www.goodcarbadcar.net/2020-us-vehicle-sales-figures-by-model/.

Tulumba, C. (2021). 2021 US Pickup Truck Sales Figures By Model. GCBC. https://www.goodcarbadcar.net/2021-us-pickup-truck-sales-figures-by-model/.

Turnbull, G. (2014, September 29). End of an Icon: The Rise and Fall of the Humvee. Army Technology. https://www.army-technology.com/features/featureend-of-an-icon-the-riseand-fall-of-the-humvee-4381884/.

U.S. Department of Energy. (2021). Comparison of Electric Vehicles. U.S. Department of Energy. https://www.fueleconomy.gov/feg/Find.do?action=sbsSelect.

US Energy Information Administration. (2004, May 1). Weekly U.S. All Grades Conventional Retail Gasoline Prices (Dollars per Gallon). https://www.eia.gov/dnav/pet/hist/LeafHandler.ashx?n=PET\&s=EMM_EPM0U_PTE_NU S_DPG\&f $=\mathrm{W}$.

Uwoghiren, J. (2020, January 14). Analyzing Twitter Users' Reflections using NLP. GitHub. https://github.com/jess-data.

Vasile, P. (2020, January 12). What's the best way to handle NaN values? Medium. https://towardsdatascience.com/whats-the-best-way-to-handle-nan-values-62d50f738fc.

Woisetschläger, D. M. (2007). Team-Sponsorship in the Formula One-Does it affect Brand Perception? Advances in Consumer Research, 34, 616-623. 
Yener, Y. (2020, November 7). Step by Step: Twitter Sentiment Analysis in Python. Towards Data Science. https://towardsdatascience.com/step-by-step-twitter-sentiment-analysis-inpython-d6f650ade58d. 